\title{
Glycans as Modulators of Plant Defense Against Filamentous Pathogens
}

\author{
Chayanika Chaliha ${ }^{1}$, Michael D. Rugen ${ }^{2}$, Robert A. Field ${ }^{2}$ and Eeshan Kalita ${ }^{1,2 *}$ \\ ${ }^{1}$ Department of Molecular Biology and Biotechnology, Tezpur University, Tezpur, India, ${ }^{2}$ Department of Biological Chemistry, \\ John Innes Centre, Norwich Research Park, Norwich, United Kingdom
}

\section{OPEN ACCESS}

Edited by: Thomas Mitchell,

The Ohio State University,

United States

Reviewed by:

William Underwood,

Agricultural Research Service (USDA),

United States

Wei Zeng,

The University of Melbourne, Australia

*Correspondence:

Eeshan Kalita

ekalita@tezu.ernet.in

Specialty section:

This article was submitted to

Plant Microbe Interactions,

a section of the journal

Frontiers in Plant Science

Received: 13 February 2018 Accepted: 11 June 2018

Published: 04 July 2018

Citation:

Chaliha C, Rugen MD, Field RA and Kalita E (2018) Glycans as Modulators of Plant Defense Against Filamentous

Pathogens. Front. Plant Sci. 9:928. doi: 10.3389/fpls.2018.00928
Plants and microbes utilize glycoconjugates as structural entities, energy reserves for cellular processes, and components of cellular recognition or binding events. The structural heterogeneity of carbohydrates in such systems is a result of the ability of the carbohydrate biosynthetic enzymes to reorient sugar monomers in a variety of forms, generating highly complex, linear, branched, or hierarchical structures. During the interaction between plants and their microbial pathogens, the microbial cell surface glycans, cell wall derived glycans, and glycoproteins stimulate the signaling cascades of plant immune responses, through a series of specific or broad spectrum recognition events. The microbial glycan-induced plant immune responses and the downstream modifications observed in host-plant glycan structures that combat the microbial attack have garnered immense interest among scientists in recent times. This has been enabled by technological advancements in the field of glycobiology, making it possible to study the ongoing co-evolution of the microbial and the corresponding host glycan structures, in greater detail. The new glycan analogs emerging in this evolutionary arms race brings about a fresh perspective to our understanding of plant-pathogen interactions. This review discusses the role of diverse classes of glycans and their derivatives including simple sugars, oligosaccharides, glycoproteins, and glycolipids in relation to the activation of classical Pattern-Triggered Immunity (PTI) and EffectorTriggered Immunity (ETI) defense responses in plants. While primarily encompassing the biological roles of glycans in modulating plant defense responses, this review categorizes glycans based on their structure, thereby enabling parallels to be drawn to other areas of glycobiology. Further, we examine how these molecules are currently being used to develop new bio-active molecules, potent as priming agents to stimulate plant defense response and as templates for designing environmentally friendly foliar sprays for plant protection.

Keywords: carbohydrates, glycans, elicitors, priming, plant defense, fungi, oomycete

\section{INTRODUCTION}

Plant cell walls are complex configurations of highly recalcitrant interlocking polysaccharides which insulate against microbial invasion and abiotic stress. Filamentous plant pathogens, which mainly comprise fungi and oomycetes, breach the plant cell wall by releasing enzymes that deconstruct polysaccharides, proteins, and lignin based polymers (Zhao et al., 2013). The resulting breakdown products that accumulate in apoplastic fluids represent the first molecular interaction 
between microbes and the plant. As such, the apoplast also represents the zone where the plants need to distinguish between symbionts and pathogens, based on their molecular signatures (Okmen and Doehlemann, 2016).

The activation of the complex array of plant innate defense mechanisms relies on the recognition of pathogen signatures by the host transmembrane pattern recognition receptors (PRRs) (Zipfel, 2014). The signatures perceived by PRRs are conserved molecular patterns called PAMPs/MAMPs (Pathogen or Microbe Associated Molecular Patterns) which are either the breakdown products resulting from microbial enzyme action or pathogenic effectors secreted by microbes to promote infection (Figures 1, 2 and Table 1; Trouvelot et al., 2014). However, pathogens also secrete effectors to mask the PTI response resulting from PAMP recognition by the host. The secretion of these effectors mediate the remodeling of the microbial cell wall due to which the pathogen is able to either escape the host defense or trigger the ETI responses (Hopke et al., 2018). This has been seen in mammalian systems, yet its importance in carbohydrate mediated interactions between plants and microbes remains to be determined.

Although PAMPs represent a broad range of molecules, which includes carbohydrates, lipids, proteins, peptides, lipopolysaccharides, glycolipids, and glycoproteins (Boller and Felix, 2009; Trouvelot et al., 2014), it is only during recent times that advances in functional glycomics have encouraged researchers to analyze the role of glycans in plant-pathogen interactions. The threat to food security from filamentous pathogens, which rely on a host of glycans to mediate pathogenesis, accounting for an estimated loss of 10-40\% of total crop production worldwide (Sobhy et al., 2014; Anderson et al., 2016) has driven intense research in this area. In turn, this had led to concepts like "sweet immunity" and "sugar enhanced defense" that explore the multi-faceted and systemic role of carbohydrates as modulators of plant immunity (Trouvelot et al., 2014; Rovenich et al., 2016).

In the context of glycan-mediated plant immunity, identification of microbial cell-surface glycans, building blocks of fungal/oomycetes cell walls (e.g., chitin and $\beta$-glucans) and bacterial glycoconjugates (e.g., lipopolysaccharide, glycoproteins, and lectins) that act as regulators of plant defense signaling, presents new perspectives to analyze and understand hostmicrobe interactions (Vidal et al., 1998; Boudart et al., 2003; Trouvelot et al., 2014). Within this review, we look at how the different classes of glycans become a part of the strategic interactions during plant-microbe interaction and their future potential as defense priming agents for plant protection. The review covers a broad range of topics, providing a brief insight that can act as a primer to an audience unfamiliar with this topic alongside those studying plant-pathogen interaction.

\section{SIMPLE SUGARS: MONO AND DI-SACCHARIDES}

Simple sugars including mono and di-saccharides are central to plant-microbe interactions, serving both as energy sources to drive the PTI and ETI responses as well as themselves acting as signaling molecules that drive signal fluxes leading to localized or systemic defense responses, when challenged with filamentous pathogens (Trouvelot et al., 2014).

\section{Glucose, Sucrose, and Associated Metabolites}

The role of the glucose sensor Hexokinase (HXK), which is responsible for the conversion of glucose to glucose 6-phosphate, has been most investigated. Among the several isoforms of HXK1, the mitochondria-associated HXK1 is central to the control of programmed cell death (PCD) during microbial pathogenesis and is also responsible for regulation of several pathogenesis related $(P R)$ genes, during HR mediated cell death (Kim et al., 2006). Glucose also activates the expression of several PR genes, of which some may require the HXK to be catalytically active. For instance, glucose mediated the induction of $P R-1$ and PR-5 in Arabidopsis in an AtHXK1 dependent manner and also Arabidopsis lines overexpressing mitochondrial HXK have higher basal transcript levels of $P R$ genes showing enhanced resistance to the necrotrophic fungal pathogen Alternaria brassicicola (Xiao et al., 2000; Rojas et al., 2014).

Sucrose has emerged as an important molecule in plant sugar signaling networks owing to recent evidences of its involvement in the modulation of innate immunity and defense responses during microbial attack (Gomez-Ariza et al., 2007; Bolouri Moghaddam and Van den Ende, 2012). It is suggested that cellwall localized invertases hydrolyze sucrose to generate glucose, which in turn act as signal fluxes that are sensed by HXKs to activate downstream defense signaling (Moore et al., 2003; Cho et al., 2009; Tauzin and Giardina, 2014). Additionally, sucrose has been seen to drive the expression of secondary metabolite synthesis pathways including anthocyanin and isoflavonoid production, as a defense response against Fusarium oxysporum in Lupinus angustifolius and in embryo axes of Lupinus luteus L. cv. Juno (Morkunas et al., 2005; Formela et al., 2014).

Trehalose and trehalose-6-phosphate (T-6-P) are considered important sugar signals, modulating defense responses through complex sugar sensing pathways (Figure 3). Trehalose induces the activation of the defense genes Phenylalanine AmmoniaLyase (PAL) and Peroxidase (POX) during wheat challenge with Blumeria graminis, the causal agent of powdery mildew disease (Reignault et al., 2001; Muchembled et al., 2006). Plant cell derived T-6-P acts as a molecular switch that negatively regulates the activity of the sucrose non-fermenting related protein kinase 1 (SnRK1). SnRK1 is a master regulator that controls sugar metabolism during biotic stresses (Hulsmans et al., 2016). KIN 10 and KIN 11 the Arabidopsis analogs of SnRK1, which have been seen to be functional under both types of stress, establish a link between sugar metabolism and the metabolic disruptions seen under pathogen attack. Rice cultivars sensitive to Magnaporthe grisea, for instance, were seen to have fewer metabolites involved in sugar metabolism, compared to the resistant varieties (Jones et al., 2011). It was later shown by Baena-Gonzalez (2010) that SnRK1 is the primary modulator repressing the energy intensive synthetic pathways and activating 


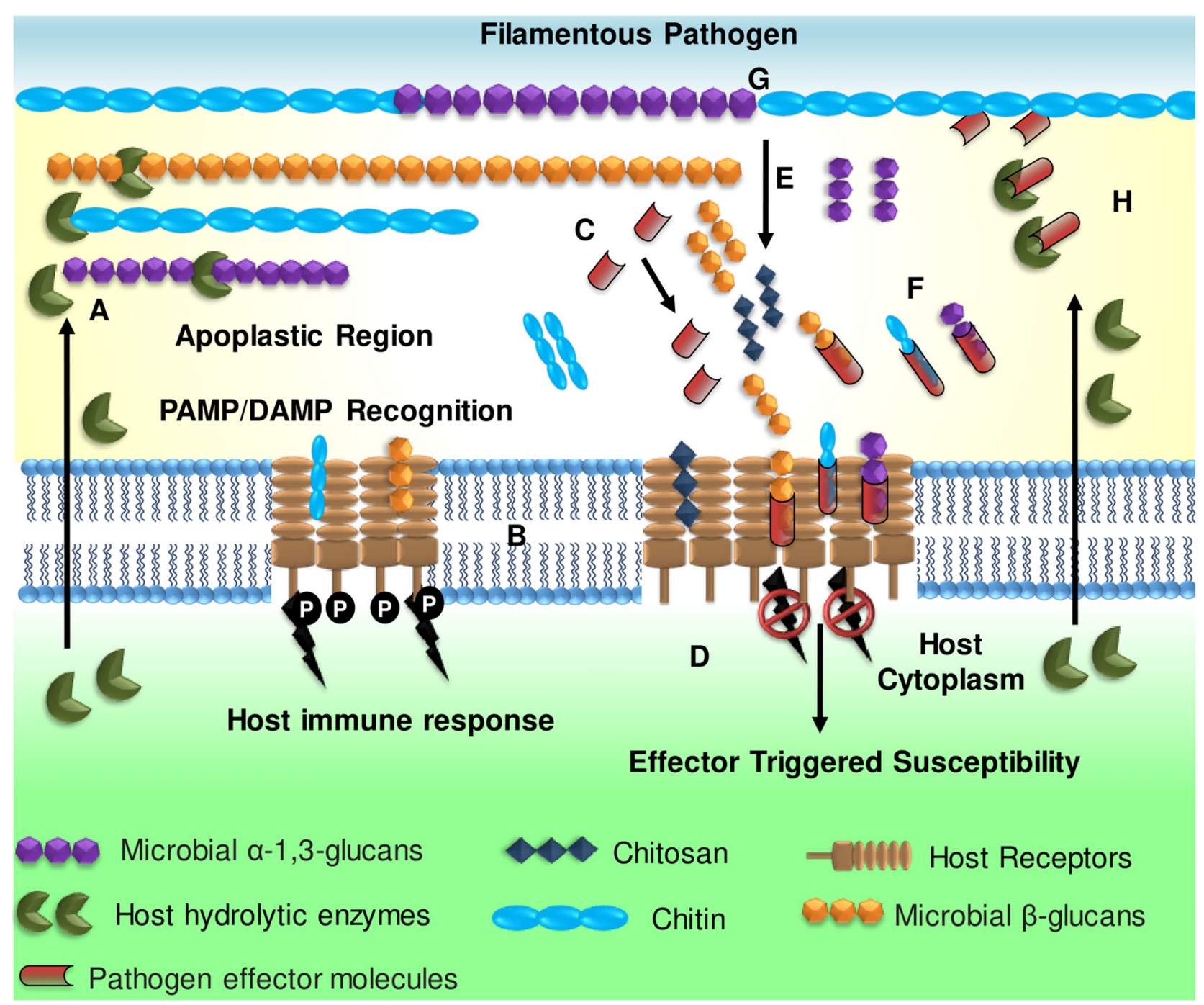

FIGURE 1 | Overview of glycan-triggered immune responses during plant-filamentous pathogen interactions. (A) Filamentous pathogen cell walls are targeted by host-derived hydrolytic enzymes, as an innate defense response resulting in the release of glycan fragments (chitin, $\alpha$ - and $\beta$-glucans). (B) The hydrolyzed glycans are recognized as PAMPs by host pattern recognition receptors (PRRs) triggering innate immune response. (C) The pathogen secretes effector molecules that (D) suppress PTI defense responses by (E) converting immunogenic chitin to the less immunogenic chitosan (F) sequestering or masking the PAMPs released, to evade detection. (G) Remodeling of the cell wall components by the pathogen (e.g., accumulation of $\alpha$-1,3-glucan) mitigates the effect of host-hydrolytic enzymes on the microbial cell wall glycans, thereby preventing hydrolysis. $\mathbf{( H )}$ Lastly, the pathogens may secrete certain effectors that directly inhibit host hydrolytic enzymes. (Adapted from Rovenich et al., 2016 and reproduced with permission from John Wiley and Sons).

catabolic pathways under stressed conditions, to restore cellular homeostasis . Interestingly, the effect of SnRK1 activation, under abiotic stresses could be reversed by the exogenous application of sucrose. Inhibition was also seen upon the external application of glucose and glucose-6-phosphate (G-6-P) (Zhang et al., 2009; Nunes et al., 2013). This repression was attributed to the fact that drops in levels of sucrose, glucose, G-6-P and T-6-P were acting as starvation signals which in turn induced SnRK1. In Arabidopsis seedlings, the increased T-6-P levels act as a "feast signal" suppressing SnRK1 activity (Morkunas and Ratajczak, 2014).

SnRK1 has also been shown to drive the expression of stress inducible genes in plants aided by the heterodimerization of S-group and C-group bZIP transcription factors (for basic region/Leu zipper motifs) leading to protection against pathogens via PCD. The response of the transcription factors to sugar levels is, however, variable as seen for Arabidopsis AtbZIP11, which is sugar inducible, while AtbZIP1, AtbZIP2, and AtbZIP53 are sugar repressible. As new insights are drawn regarding the role of sugars in modulating the metabolic state and defense responses under pathogen attack, gaps in the understanding of signaling pathways continue to emerge. With respect to sucrose, glucose, G-6-P, and T-6-P there is sufficient evidence to suggest that they function as signals reflecting the general metabolic health of the plants and also behave as systemic defense modulators in certain cases. However, various questions remain unanswered regarding 


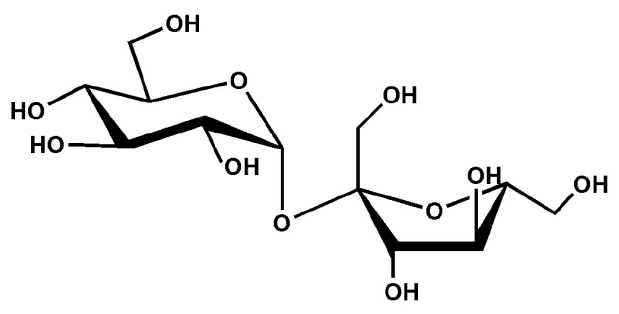

Sucrose

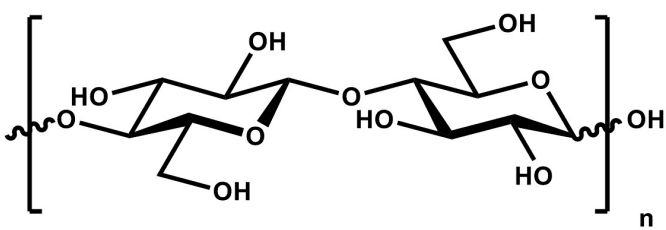

Cellodextrin

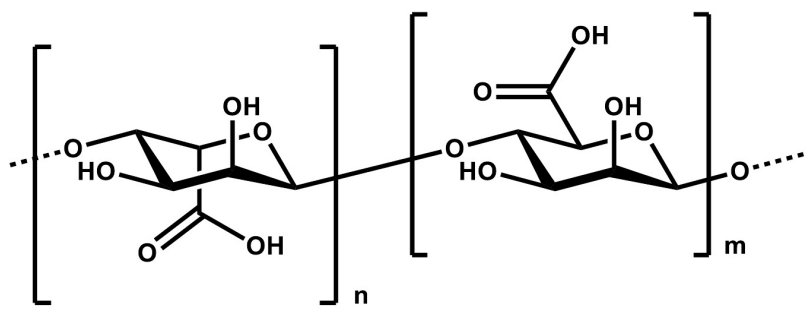

Aginate

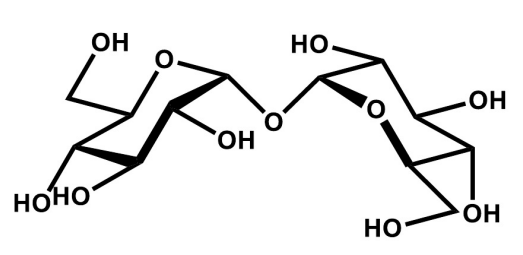

Trehalose<smiles>OC[C@@H](O)[C@@H](O)[C@H](O)[C@H](O)CO</smiles>

Mannitol

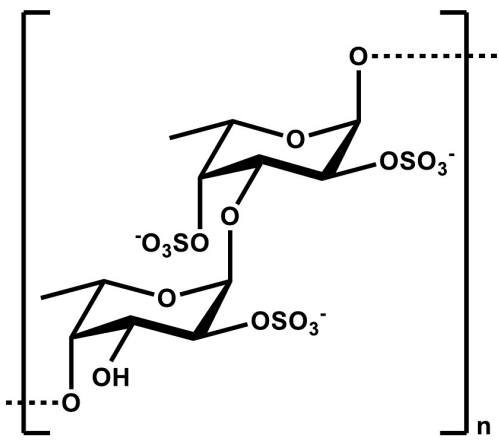

Sulfated fucan

FIGURE 2 | Chemical structures of oligosaccharides showing elicitor activity.

the site and mechanism of action for these glycans, as well as their holistic roles in plant defense.

\section{Galactinol, Raffinose, and Related Oligosaccharides}

Galactinol in plants is present as a precursor for the synthesis of the raffinose family oligosaccharides (Figure 4), which serve as an osmoprotectant of plants, as a transporter of sugar in phloem sap, and as storage sugars (Sengupta et al., 2015). Soybean plants under drought stress conditions, when pretreated with $\mathrm{H}_{2} \mathrm{O}_{2}$, were seen to have increased levels of galactinol which is known to function as an ROS scavenger (Ishibashi et al., 2011; Savvides et al., 2016). A similar phenomenon was also observed in Arabidopsis where oxidative stress induced the expression of high levels of galactinol synthase (GolS) (Nishizawa et al., 2008; Petrov et al., 2015). This enzyme catalyzes the first step toward the biosynthesis of galactinol which was first detected in a crude extract of maturing pea seeds (Zhou et al., 2017). The induction of the GolS gene leading to the biosynthesis of galactinol has mostly been studied in relation to osmotic stresses across various plants such as Brassica napus L., Coffea arabica L., Salvia miltiorrhiza, grapevine, Medicago falcata, chestnut, and Cicer arietinum L. The first evidence of galactinol being involved in inducing systemic resistance during biotic stress was observed during the interaction between Pseudomonas chlororaphis and cucumber or tobacco plants. Galactinol enhanced the accumulation of defenserelated genes PR1a, PR1b, and NtACS1 (Nicotiana tabacum 1-aminocyclopropane-1-carboxylic acid synthase 1), which in turn enhanced resistance against Botrytis cinerea and Erwinia carotovora in pathogen challenged cucumber and tobacco plants (Kim et al., 2008). Preliminary investigations on Camellia sinensis Gols gene (CSGolS) have shown that CsGolS1 regulation was mainly related to abiotic stresses such as water deficiency, low temperature, and ABA treatment. On the other hand, significant regulation of CsGols2 and CsGols3 was seen in relation to 
TABLE 1 | Various carbohydrate elicitors inducing defense responses in plants.

\begin{tabular}{|c|c|c|c|c|}
\hline $\begin{array}{l}\text { Carbohydrate } \\
\text { elicitors }\end{array}$ & Source & $\begin{array}{l}\text { Plants eliciting defense } \\
\text { responses }\end{array}$ & Plant defense responses & Reference \\
\hline $\begin{array}{l}\text { Sugars (Glucose, } \\
\text { G-6-P,Sucrose, } \\
\text { Trehalose, T-6-P) }\end{array}$ & Plant & $\begin{array}{l}\text { Arabidopsis, Lupinus } \\
\text { angustifolius, wheat }\end{array}$ & $\begin{array}{l}\text { Activation of pathogen resistance (PR) genes, } \\
\text { phenylalanine ammonia-lyase (PAL), and } \\
\text { peroxidase (POX) activity }\end{array}$ & $\begin{array}{l}\text { Xiao et al., 2000; Reignault et al., } \\
\text { 2001; Zhang et al., 2009; Nunes } \\
\text { et al., } 2013\end{array}$ \\
\hline$\beta$-glucans & Microbial cell wall & $\begin{array}{l}\text { Arabidopsis, leguminous } \\
\text { plant, grapevine, alfalfa, } \\
\text { tobacco }\end{array}$ & $\begin{array}{l}\text { Induction of chitinase and PAL activity, } \\
\text { synthesis of isoflavanoid and phytoalexins }\end{array}$ & $\begin{array}{l}\text { Klarzynski et al., 2000; Caillot et al. } \\
\text { 2012; Fesel and Zuccaro, } 2016\end{array}$ \\
\hline Laminarin & Brown algae & Tobacco, grapevine & $\begin{array}{l}\text { Induction of calcium influx, oxidative burst, } \\
\text { activation of PR genes }\end{array}$ & $\begin{array}{l}\text { Klarzynski et al., 2000; Aziz et al., } \\
2003\end{array}$ \\
\hline Chitin & Fungal cell wall & Rice, barley, Arabidopsis, & $\begin{array}{l}\text { Induce hypersensitive response, mitogen } \\
\text { activated protein kinase (MAPK) pathway, PR } \\
\text { genes, chitinase activity, PAL activity, } \\
\text { phytoalexins accumulation, callose deposition }\end{array}$ & $\begin{array}{l}\text { Yamada et al., 1993; Kishimoto } \\
\text { et al., 2010; Tanaka et al., 2010; } \\
\text { Yamaguchi et al., 2013, }\end{array}$ \\
\hline Chitosan & Fungal cell wall & $\begin{array}{l}\text { Pea, dicotyledonous } \\
\text { species, melon }\end{array}$ & $\begin{array}{l}\text { Induce PR genes, chitinase activity, PAL activity, } \\
\text { phytoalexin accumulation }\end{array}$ & $\begin{array}{l}\text { Kohle et al., 1985; Conrath et al., } \\
\text { 1989; Burkhanova et al., } 2007\end{array}$ \\
\hline Cellodextrins & Plant & Grapevine & $\begin{array}{l}\text { Activation of PR genes, induction of calcium } \\
\text { influx, oxidative burst, phytoalexin accumulation }\end{array}$ & $\begin{array}{l}\text { De Lorenzo and Ferrari, 2002; Aziz } \\
\text { et al., } 2007\end{array}$ \\
\hline Alginate & Sea weed & Soybean, rice & $\begin{array}{l}\text { Phytoalexins accumulation, activation of PR } \\
\text { genes encoding PAL, induction of POX activity }\end{array}$ & $\begin{array}{l}\text { An et al., 2009; Zhang S. et al., } \\
2015\end{array}$ \\
\hline Fucans & Sea weed & Tobacco & Induce PAL activity, PR genes & $\begin{array}{l}\text { Kombrink and Somssich, 1995; } \\
\text { Klarzynski et al., } 2003\end{array}$ \\
\hline
\end{tabular}

biotic stresses such as E. oblique (moth) attack, SA, and MeJA treatment (Zhou et al., 2017). Although the Gols gene has been extensively studied under abiotic stress, the regulation of the galactinol levels by this gene during biotic stress (pest attack and microbial invasion) needs to be further investigated to understand the underlying mechanisms. Furthermore, the roles played by galactinol derivatives in response to stresses including pathogen attack remain to be elucidated (Sengupta et al., 2015).

\section{Polyols}

Polyols, often referred to as sugar alcohols, are the reduced form of aldose and ketose sugars (Noiraud et al., 2001). Mannitol is a soluble polyol which is structurally related to the aldohexose mannose. It is widely present in bacteria, algae, fungi, and more than 100 species of higher plants including many crops such as celery, olive, and carrot (Patel and Williamson, 2016). Mannitol is an osmoprotectant, contributing to salt tolerance in plants and it has been demonstrated to be an in vitro quencher of reactive oxygen species that limits cell damage (Jennings et al., 2002). Interestingly, mannitol is also a common metabolite in most filamentous plant pathogens including ascomycetes, basidiomycetes, deuteromycetes, and zygomycetes (Jennings, 1985; Solomon et al., 2007). The fungal pathogens Alternaria alternata, A. brassicicola, and Cladosporium fulvum are reported to secrete mannitol when they encounter plant tissues or extracts (Williamson et al., 2013). Mannitol accumulation was first documented in the apoplast of tomato leaves upon infection with a virulent strain of C. fulvum, but was absent in leaves infected with the avirulent stain (Joosten et al., 1990). The role of mannitol as a pathogenicity factor was further consolidated by reports stating greatly reduced virulence of $A$. alternate mannitol synthesis knockout mutants $(\Delta m t d h / \Delta m 1 p d h)$ (Vélëz et al., 2007). In light of such reports, mannitol is speculated to be involved in quenching ROS-mediated plant defenses by virtue of its antioxidant properties (Calmes et al., 2013). The current opinion in this regard suggests that mannitol secretion by filamentous pathogens serves as a self-defense strategy against plant defense responses and may also be a means of obstructing the plant defense signaling pathways by blocking plant mediated ROS signals (Juchaux-Cachau et al., 2007). This aspect has been recently reviewed by Patel and Williamson (2016) to present a mechanistic hypothesis (Figure 5) regarding the interplay between mannitol and mannitol dehydrogenase during pathogenesis of the mannitol-secreting pathogens and how it may be balanced between detection of pathogens by plants and evasion of defense response by the pathogen.

\section{OLIGOSACCHARIDES}

Most oligosaccharides implicated in plant-pathogen interactions are generated by the enzymatic degradation of polysaccharides from the structural constituents of fungal cell wall or pathogen virulence factors (Zhang S. et al., 2015). The activity of these oligosaccharides is highly dependent on their degree of polymerization (DP) (Trouvelot et al., 2014).

\section{$\beta-1,3-/ \beta-1,6$-glucans}

$\beta$-1,3-/ $\beta$-1,6-Glucans based oligosaccharides have been extensively explored in view of their involvement in plantpathogen interactions for several decades (Fesel and Zuccaro, 2016). $\beta$-glucans were first isolated from crude or enriched fractions of Phytophthora sojae mycelial cell wall hydrolysate, which mediated plant defense by the induction of PAL activity in plants (Ayers et al., 1976; Ebel et al., 1976). In tobacco and Arabidopsis, sulfated $\beta$-1,3-glucans were able to induce a SA mediated defense reactions conferring resistance to tobacco 
(extracellular) ? Transport/Sensing/Invertase

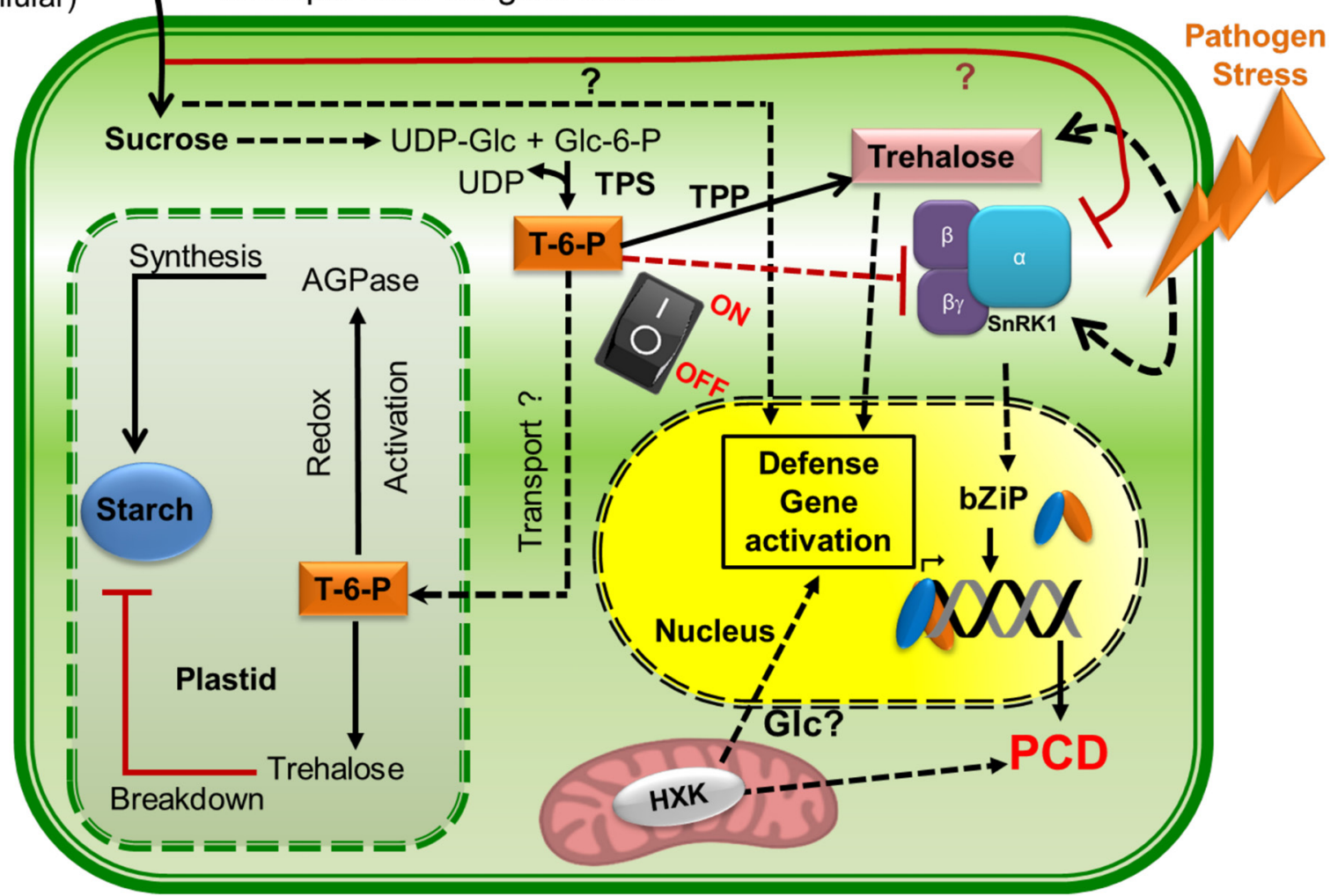

FIGURE 3 | Sugar fluxes regulating defense responses under pathogen attack. Trehalose-6-phosphate (T-6-P) is central to the metabolic switch between energy intensive processes like starch synthesis and low sugar stress conditions (when under pathogen attack or during plant defense signaling). T-6-P regulates the switch between these two conditions by regulating the multi-functional heterotrimeric stress regulator, SnRK1. SnRK1 can perceive low sugar stress and mediate defense against pathogens through post translational modification of key metabolic enzymes, activating PCD and bZIP (basic leucine zipper) mediated transcriptional reprogramming. Trehalose on the other hand can also sense pathogen stress and respond by activating defense genes and blocking the energy intensive starch biosynthesis. Sucrose regulates defense signaling both positively and negatively by activating secondary metabolite production under low sugar conditions on one hand and inhibiting SnRK1 on the other, during normal conditions. Additionally, the mitochondrial HXKs are also implicated in activating PCD and defense gene activation during pathogen attack. However, little is known if Glucose mediates the process. Thus, the components of signalling pathway of sugars (like sucrose, glucose and trehalose) that maintains the balance between stress conditions and homeostatsis are yet to be discovered and are indicated by "?" in the figure.

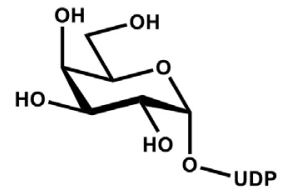

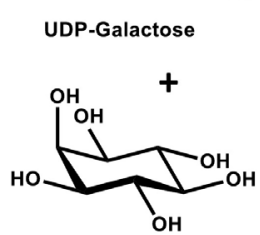

Myo-inositol

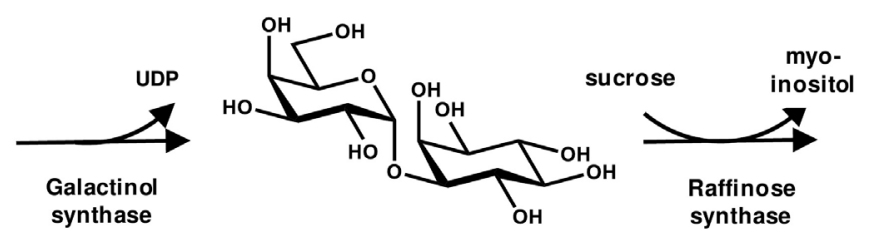

Galactinol

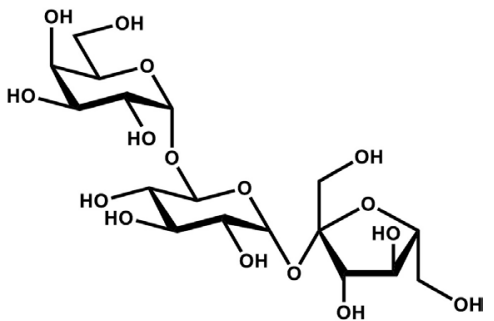

Raffinose

FIGURE 4 | The biochemical pathway of Raffinose Oligosaccharide synthesis.

mosaic viruses (Menard et al., 2004). Laminarin, a $\beta-1,3-$ glucan, derived from the brown algae Laminaria digitata was seen to elicit a variety of defense reactions in tobacco plants.
Treatment of tobacco with laminarin as an elicitor led to the enhanced activity of PAL, caffeic acid, $O$-methyl transferase, and lipoxygenase, accumulation of SA, and transcriptional activation 


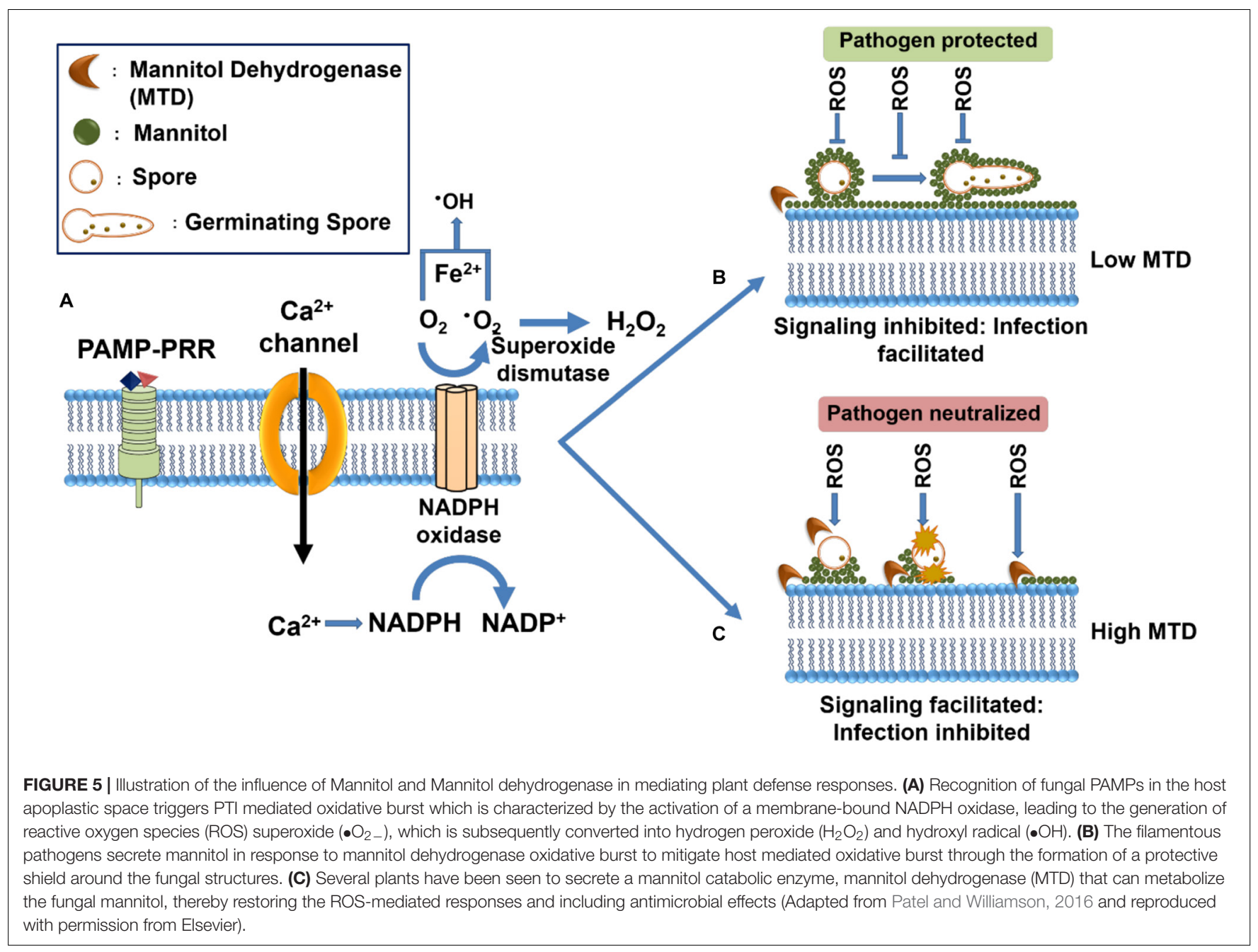

of PR proteins. These events resulted in activation of induced resistance against the soft rot pathogen E. carotovora (Klarzynski et al., 2000). Using laminarin elicitors on grapevine induced early defense responses including calcium influx, oxidative burst, extracellular alkalization of the culture medium, and activation of mitogen-activated protein kinases (MAPK) (Aziz et al., 2003). Laminarin in later stages of host defense induced the expression of defense genes associated with the octadecanoid and phenylpropanoid pathways leading to a significant protection of grapevine leaves against $B$. cinerea and Phomopsis viticola. However, HR mediated cell death was totally absent in these plants (Aziz et al., 2003). In most cases $\beta$-1,3-glucans and laminarin have DPs between 10 and 16 which are often referred to as optimal for induction of plant defense responses (Navazio et al., 2002; Galletti et al., 2008; Vorholter et al., 2012). However, Fu et al. (2011) have demonstrated using tobacco cell suspensions that $\beta$-1,3-glucans having DPs as low as $2-10$, provide a higher protection against tobacco mosaic virus compared to those with higher DP (25-40) (Fu et al., 2011). Similarly, in Oryza sativa cell suspensions $\beta$-1,3-glucan oligomers with a DP $\geq 4$ were shown to stimulate chitinase activity while those with DP 6 acted as inducers of PAL activity (Inui et al., 1997).
Plants have been seen to respond differently to structurally distinct forms of $\beta$-glucans, as seen in soybean and rice which are able to recognize only branched $\beta$-glucans (Cheong and Hahn, 1991; Yamaguchi et al., 2013) whereas tobacco recognizes the linear $\beta$-1,3-glucans. With respect to the response to chemically modified glucans as elicitors, acetylated oligoglucuronans having DP $\geq 14$ could induce the transient production of $\mathrm{H}_{2} \mathrm{O}_{2}$ and defense gene expression (PAL, Chitinase and Polygalacturonase inhibiting protein). This strategy was effective in reduction of $B$. cinerea infection of grapevine leaves upon treatment with these acetylated oligoglucuronans (Caillot et al., 2012). In the case of natural laminarin, chemically sulfated analogs with DP $>5$ were seen to be effective in stimulating the SA signaling pathway leading to protection against pathogens in tobacco and Arabidopsis plants (Menard et al., 2004). A hepta$\beta$-glucan isolated from culture medium during germination of Phytophthora megasperma f. sp. glycinea was found to elicit the synthesis of isoflavonoid phytoalexins in soybean cotyledons (Sharp et al., 1984a,b). This interaction was seen to stimulate the induction of localized $\mathrm{HR}$ mediated resistance against P. megasperma f. sp. glycinea in several other legumes namely soybean, alfalfa (Medicago sativa), bean (Vicia faba), lupin 
(Lupinus albus), pea, Medicago truncatula, and Lotus japonicus (Cosio et al., 1996; Cote et al., 2000).

The recognition of fungal $\beta$-glucans by animal cells is known to induce the production of inflammatory chemokines/cytokines such as TNF $\alpha$, IL-1b, IL-10, IL-6, IL-23, CCL2, CCL3, etc., when perceived by the homo-dimerization and phosphorylation of Dectin-1 (Brown and Gordon, 2003; Drummond and Brown, 2011). Cell signaling in case of Dectin-1 can proceed through both SYK-dependent (Spleen Tyrosine Kinase) and independent pathways (RAF1-dependent), bringing about a horde of effects ranging from internalization of pathogen for antigen-presentation to cytokine/caspase activation. Dectin-1 consists of an extracellular C-type lectin domain that is connected to the plasma membrane by a stalk region which protrudes in to the extracellular space. The cytoplasmic C-terminus contains an immunoreceptor tyrosine-based activation motif (ITAM). Dectin- 1 is primarily localized on the surface of macrophages and to a lesser extent on dendritic cells that binds to $\beta$-1,3-glucans and mixed $\beta-1,3 / 1,6$-glucans like laminarin, zymosan, and complete yeast cells. The intracellular ITAM motif is phosphorylated by SRC, a tyrosine-protein kinase, upon recognition of $\beta-1,3-$ glucans which activates the downstream Syk signaling cascade leading to immunogenic responses (Levitz, 2010). However, the phosphorylation of ITAM is preceded by the dimerization of two Dectin-1 receptors, following $\beta$-1,3-glucan binding (Brown et al., 2007). The interaction between $\beta$-glucan and Dectin- 1 is mediated through the Trp221 and His223 amino acids on the C-type lectin domain of Dectin-1 (Adachi et al., 2004) which shares a $30 \%$ homology with A. thaliana and soybean, C-type lectin (Greeff et al., 2012; Singh and Zimmerli, 2013). However, the structure of the $\beta$-glucan binding groove in the corresponding plant C-type lectin domain is not known and it is speculated that the binding of a more complex $\beta$-glucan could be accommodated by a different set of amino acids in the plant Dectin-1 orthologs (Brown et al., 2007). Dectin-2 and Dectin-3 hetero-dimers were reported to recognize $\alpha$-mannans as PAMPS, during the Candida albicans infection of mice. The recognition of $\alpha$-mannans by Dectins 2 and 3 is mediated by the ITAM-containing cytoplasmic adaptor protein $\mathrm{FcR} \gamma$, as they themselves are devoid of the ITAM motifs on the cytoplasmic end. The activation and phosphorylation of the Dectin 2 and 3 was reported to induce the production of NF- $\mathrm{KB}$ and pro-inflammatory cytokines such as TNF- $\alpha$, IL10, IL12, and IL-6 (Zhu et al., 2013). However, no plant analogs for Dectin 2/3 have been reported so far.

Although various findings have shown a prominent role of $\beta$-glucan in priming plant defense, the putative sequence and domain structure for the plant $\beta$-glucan receptor is not known. One of the reasons could be that such studies have mostly been restricted to the Col-0 ecotype of A. thaliana, which is not known to elicit a strong immune response against $\beta$-glucan treatment (Fesel and Zuccaro, 2016). Furthermore, the work done on $\beta$-glucan mediated immunity during fungusanimal interactions appears to provide leads toward the better understanding of $\beta$-glucan perception in plants, wherein plant Dectin-1 homologs are believed to harbor a mammalian SYK-like domain, instead of the ITAM domain (Fesel and Zuccaro, 2016). Based on the information available, a schematic depicting the $\beta$-glucan and $\alpha$-mannan mediated immunity in animals and the hypothetical model of its plant counterpart is depicted in Figure 6. A genome wide survey of the available Arabidopsis ecotype resources or investigation of the $\beta$-glucan and $\alpha$-mannan perception in other model plants could possibly unearth the missing links to complete the picture.

\section{Cellodextrins}

Cellodextrins are a group of oligosaccharides that consist of a linear $\beta$-1,4- linked glucose backbone, which are the endproducts of cellulose degradation in plants. It has been reported that cellodextrin treatment of plant cells leads to the activation of PAL genes, which enhances synthesis of lignin, SA, and phytoalexin as an innate immune response. They in turn activate acidic (Chit3, Chit4c) and basic (Chit1b) chitinases and $\beta-1,3-$ glucanase which are responsible for hydrolysis of chitin and $\beta$-1,3-glucans in fungal cell walls (Farmer et al., 1991; De Lorenzo and Ferrari, 2002). Exogenous application of cellodextrin as an elicitor was also seen to activate protection against $B$. cinerea by triggering induction of oxidative burst, defense-related genes, elevation of cytosolic $\mathrm{Ca}^{2+}$, and stimulation of chitinase and $\beta$-1,3-glucanase activity (Aziz et al., 2007). In grapevine, the generation of $\mathrm{H}_{2} \mathrm{O}_{2}$ and subsequent oxidative burst was highest in response to heptasaccharide cellodextrins (Aziz et al., 2007). Also, in Arabidopsis, treatment with cellobiose induced the innate immune responses such as increased cytosolic calcium and activation of MAPK pathway in response to Pseudomonas syringae infection (De Azevedo Souza et al., 2017). However, the fundamentals of cellodextrin signaling still remain unclear and the correlation between the degree of polymerization and intensity of defense response needs further investigation.

\section{Chitin and Chitin Derivatives}

Chitin, a polymer of $\mathrm{N}$-acetylglucosamine, is a major constituent of fungal cell walls and is the most well characterized filamentous PAMP (Shibuya and Minami, 2001). It has been seen to stimulate phytoalexins and trigger the MAPK based defense signaling in response to Magnaporthe oryzae challenge of rice, thereby providing a systemic resistance (Yamada et al., 1993; Yamaguchi et al., 2013). The first PRR for chitin, Chitin Elicitor Binding Protein (OsCEBiP), was identified as a plasma membrane localized receptor in rice cells, which was responsible for defense signal transduction (Miya et al., 2007; Kishimoto et al., 2010). In barley, the basal resistance against $M$. oryzae was seen to develop upon the recognition of chitin by the OsCEBiP homolog, HvCEBiP (Tanaka et al., 2010). The chitin PRR in Arabidopsis, AtCERK1 (also known as RLK1/LYK1) contains additional extracellular carbohydrate binding lysine motifs (LysMs), as well as an intracellular kinase domain essential for chitin based defense signaling (Egusa et al., 2015). Recent discoveries on Arabidopsis PRR have shown that AtCERK receptor also mediates recognition of $1,3-\beta-\mathrm{D}-(\mathrm{Glc})_{6}$, a hexasaccharide from the necrotrophic fungus Plectosphaerella cucumerina which induces innate defense responses such as increased levels of cytosolic $\mathrm{Ca}^{2+}$, activation of MAPKs cascades and elevated expression of PR proteins (Melida et al., 2018). Chitin oligosaccharides when used as elicitors were reported 


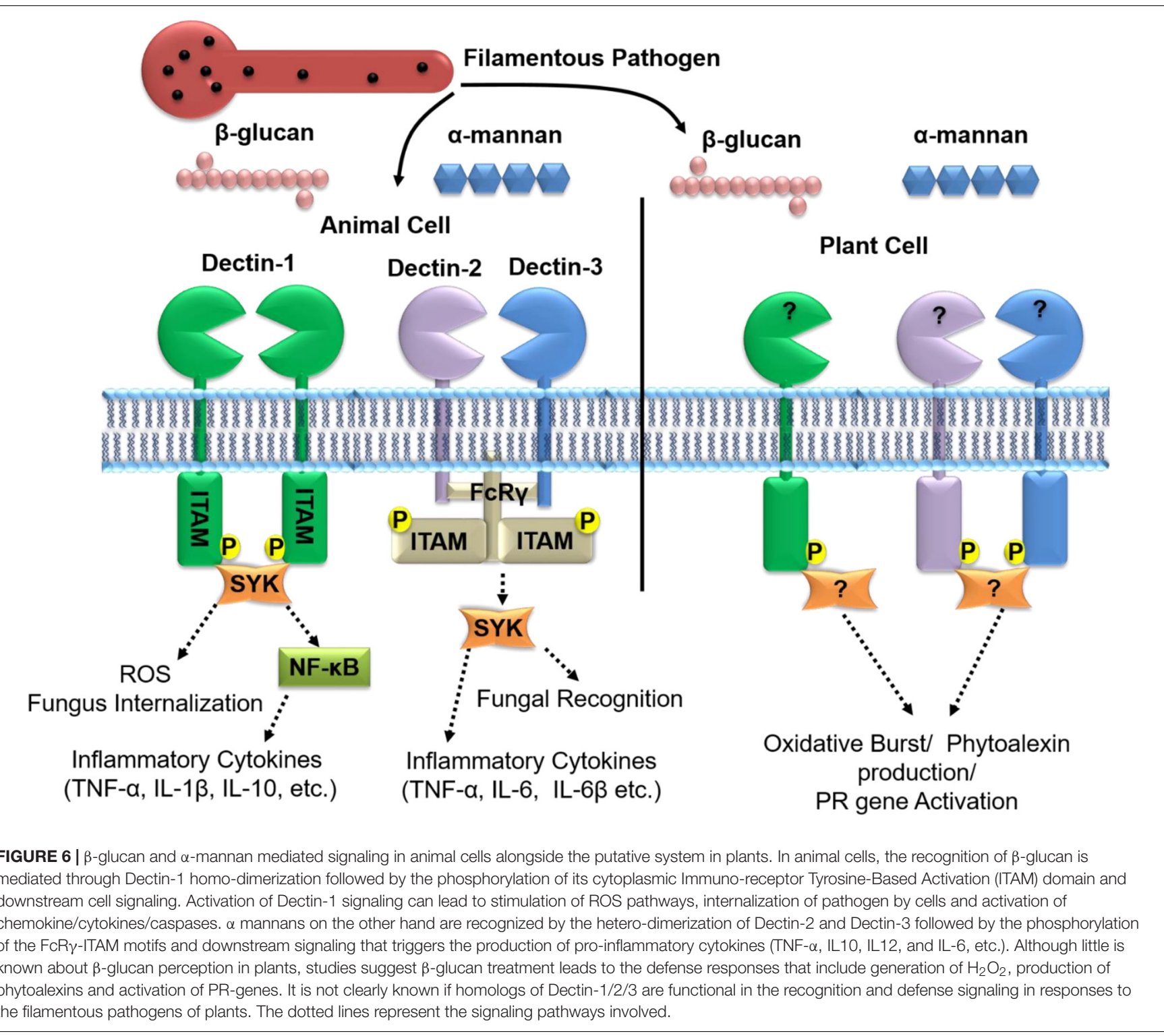

to induce the expression of pathogenesis-related protein, PR-10 and generation of ROS in both suspension-cultured rice cells and Arabidopsis seedlings (Akimoto-Tomiyama et al., 2003). In a recent study, the interaction between Phytophthora palmivora and $L$. japonicus led to the rapid transcript accumulation of LYS12, a LysM receptor protein of the NFR5-type, which could control the progression of disease by regulating defenses genes like POX, Germin-like protein, and Chitinase. Further, LYS12 mutants responded to treatments with glycan elicitors such as chitin oligomers and $\beta$-1,3- and $\beta-1,6$-glucan. It is speculated that there could be other functional components in the perception and signaling of these elicitors as LYS12 lacks the ATP binding loop and the typical Asp-Phe-Gly (DFG) motif in subdomain VII, essential for signaling. Also, several LysM receptors have been found to recognize and distinguish pathogenic/mutualistic carbohydrate signatures emerging from GlcNAc derived and microbial exopolysaccharide sources. It is therefore plausible that LYS12 is involved in monitoring carbohydrate PAMPs produced by $P$. palmivora as well as the damage associated signatures emerging from the host plant, thereby regulating disease progression (Fuechtbauer et al., 2018).

Chitosan, $\beta$-1,4-linked glucosamine is a deacetylated derivative of the chitin that forms a major component of many fungal cell walls, including those of fungal pathogens. Chitosan or its fragments have been shown to induce defense responses in dicotyledonous plant species like soybean and parsley mediated by the synthesis of callose, a $\beta$-1,3-glucan polymer (Kohle et al., 1985; Conrath et al., 1989). In melon plants, chitosan oligomers were shown to stimulate chitinase activity, while in wheat, treatment with chitosan oligosaccharides induced lignin deposition and increased phenolic acids level, in leaves (Burkhanova et al., 2007).

Chitin oligosaccharide derivatives bearing lipid modifications are known as lipochitooligosaccharides and act as microbial 
signals to initiate symbiotic association of arbuscular mycorrhizal symbiosis (Myc factors) and root-nodule symbiosis (Nod factors) (Zipfel and Oldroyd, 2017). On the other hand, chitin oligosaccharide tetramers and heptamers have been reported to induce oscillations of $\mathrm{Ca}^{2+}$ levels in the cell nucleus during symbiotic association in various legumes pea, $M$. truncatula and L. japonicus and rice (Sun et al., 2015). Thus chitin and its oligosaccharide derivatives acting either as defense elicitors or symbiosis activating signals may begin to answer how plants distinguish between friendly and pathogenic interactions in the apoplastic space. However, the role of the glycans in the interplay between the defense and symbiotic signaling networks and how plant signaling processes discern and deliver specific outcomes, remains to be unraveled.

\section{Alginate and Fucans}

Alginate oligomers are formed by depolymerization of alginates obtained from sea weed that are made up of alternating blocks of L-glucuronic and D-mannuronic residues (Gonzalez et al., 2013). Alginate oligomers are gaining increasing attention as new elicitor materials for inducing plant defense machinery by stimulating the accumulation of phytoalexin and inducing PAL activity in soybean cotyledons (An et al., 2009). Furthermore, alginate oligosaccharides rich in polymannuronate are reported to activate defense responses in $O$. sativa against $M$. oryzae by inducing increased level of PAL, phytoalexin production, and POX activity (Zhang S. et al., 2015).

Sulfated fucan oligosaccharides made up of mono- and disulfated fucose units alternatively bound by $\alpha-1,4$ - and $\alpha-1,3$ glycosidic linkages have been shown to be strong inducers of PAL, in tobacco cell suspension cultures (Kombrink and Somssich, 1995; Klarzynski et al., 2003). Inoculation of tobacco leaves with these fucan oligosaccharides resulted in the accumulation of several PR proteins and the development of jasmonate mediated systemic resistance toward TMV (Klarzynski et al., 2003).

\section{GLYCOPROTEIN AND LECTINS}

Alongside secreted protein effectors that destroy plant cell integrity filamentous pathogens are known to secrete small proteinaceous molecules that induce necrosis, shrinkage of cytoplasm, silencing of defense genes, electrolyte leakage, and generation of ROS in their hosts. These secreted molecules not only contribute to invasion and absorption of nutrients, but also assist in establishing necrotrophic/hemibiotrophic lifestyles by inducing HR-mediated cell death (Gonzalez et al., 2017). The first report of glycoproteins being involved as an elicitor that induced the defense related phytoalexin production was identified in P. megasperma and parsley interactions (Nurnberger et al., 1994). Much later the glycoprotein, $B c G s 1$ produced from the culture filtrate of the necrotrophic fungus $B$. cinerea was seen to act as a necrosis-inducing elicitor that activated the typical HR as well as components of the SA, JA, and ET defense pathways, in tomato. BcGs 1 treatment of tomato plants was found to induce the SA- dependent defense marker PR-1a, Prosystemin, a known elicitor of JA defense signaling and the tomato protein kinase 1 (TPK1b), which is an ET-mediated shared defense signal for protection against necrotrophic fungi and herbivorous insects. (Zhang Y. et al., 2015). However, the interaction between the SA, JA, and ET defense pathways, for rendering defense remains to be investigated. Earlier studies on the $B$. cinerea protein secretome have also shown the presence of an abundantly secreted glycoprotein, $B c$ IEB1, with unknown function (Espino et al., 2010). Work on the structural analysis of the BcIEB1 glycoprotein has shown two serine/threoninerich residues glycosylated with $\alpha$-1,2-/ $\alpha$-1,3-linked mannose (Gonzalez et al., 2012, 2014). Recently, the elicitor function of BcIEB1 glycoprotein was discovered by Frias et al. (2016), wherein $B c$ IEB1 expressed in yeast when assayed as a purified elicitor on tobacco, tomato, onion, and Arabidopsis, was able to induce defense responses against $B$. cinerea. The elicitor activity of the BcIEB1 protein induced ROS burst, electrolyte leakage, seedling growth inhibition, cytoplasm shrinkage and cell autofluorescence (Frias et al., 2016). Further studies on the BcIEB1 elicitor by Gonzalez et al. (2017) led to the discovery of the tobacco plant osmotin, a stress response protein, a member of the PR5 family, as the PPR of BcIEB1 glycoprotein. In a separate study, osmotin also was found to accumulate in plants as a response to invasion of fungal pathogens, leading to activation of PCD in fungi, lysis of fungal membranes and promoting the hyperaccumulation of osmolyte proline, which quenches ROS. Hence, the roles and diversity of effectors and their corresponding plant receptors extend well beyond the conventional effectors of a proteinaceous nature to involve many diverse molecules and pathways.

Glycan-binding lectin proteins are reported to regulate many of the defense signaling pathways during host-microbe interactions and immune responses (Silipo et al., 2010). Lectins mediate the recognition of plant pathogens upon perception of characteristic epitopes or damage-associated patterns, using protein-protein interactions as well as proteinglycan interaction (Lannoo et al., 2014). Lectin domain containing receptor-like kinases (LecRLKs) involved in pathogen recognition including LecRK-I.9 from Arabidopsis and Pi-d2 from rice ( $O$. sativa) are reported to act against the oomycete pathogen Phytophthora brassicae and the ascomycete M. oryzae, respectively (Weidenbach et al., 2016). In LecRK, the extracellular lectin domain of LecRK is composed of a conserved hydrophobic groove that helps in the recognition of glycans (Andre et al., 2005; Wang and Bouwmeester, 2017). LecRK-I.9 domain in Arabidopsis interacts with oligosaccharides via two tripeptide Arg-GlyAsp (RGD) in the lectin domain (Gouget et al., 2006). Also, extracellular ATP released by plants upon pathogen invasion acts as a ligand perceived by LecRk-I.9 domain (Choi et al., 2014). However, insights into the mechanism regulating both of these processes and how pathogens adapt to LecRK-mediated defense remains to be seen.

\section{GLYCOLIPIDS}

Lipopolysaccharide (LPS) is a vital structural component of the outer layer of Gram negative bacteria with three distinct 
functional domains which include: the lipophilic lipid A (LA) the di-glucosamine moiety which carries 4-7 fatty acids, an oligosaccharide core region, and the $\mathrm{O}$-antigen region consisting of a variable number of oligosaccharide repeats (Alexander and Rietschel, 2001). The oligosaccharides in LPS act as a signaling moiety during induced immunity while the LA domain is recognized, even at picomolar concentrations, as a PAMP through different extra- and intra-cellular LPS sensors (Whitfield and Trent, 2014). The LPS sensing receptor in plants is RLK LORE (Lipooligosaccharide-specific Reduced Elicitation), which belongs to the plant-specific class of bulb-type lectin S-domain1 kinases (SD-RLKs). RLK LORE can sense Pseudomonas LPS as PAMP in Arabidopsis and other crucifers triggering typical PTI responses (Ranf et al., 2015). The significance of RLK
LORE in LPS perception was demonstrated by restoration of LPS sensitivity in LPS-insensitive tobacco plants through the expression of RLK LORE.

LPS mediated defense signaling is well characterized in the mammalian system where it binds to the LPS receptor, TLR4/MD-2 (toll-like receptor 4/myeloid differentiation factor2 ), to trigger activation of phagocytosis, production of proinflammatory cytokines, and interferons and antimicrobial peptides (Figure 7; Beutler et al., 2001; Tan and Kagan, 2014). The inflammatory cascade can be activated directly by the recognition of the bacterial LPS by the mammalian glycoprotein CD14, in a TLR independent fashion. Alternatively, CD14 mediates the transfer of the bacterial LA by the mammalian serum protein LPS-binding protein (LBP), in TLR dependent fashion. Taking

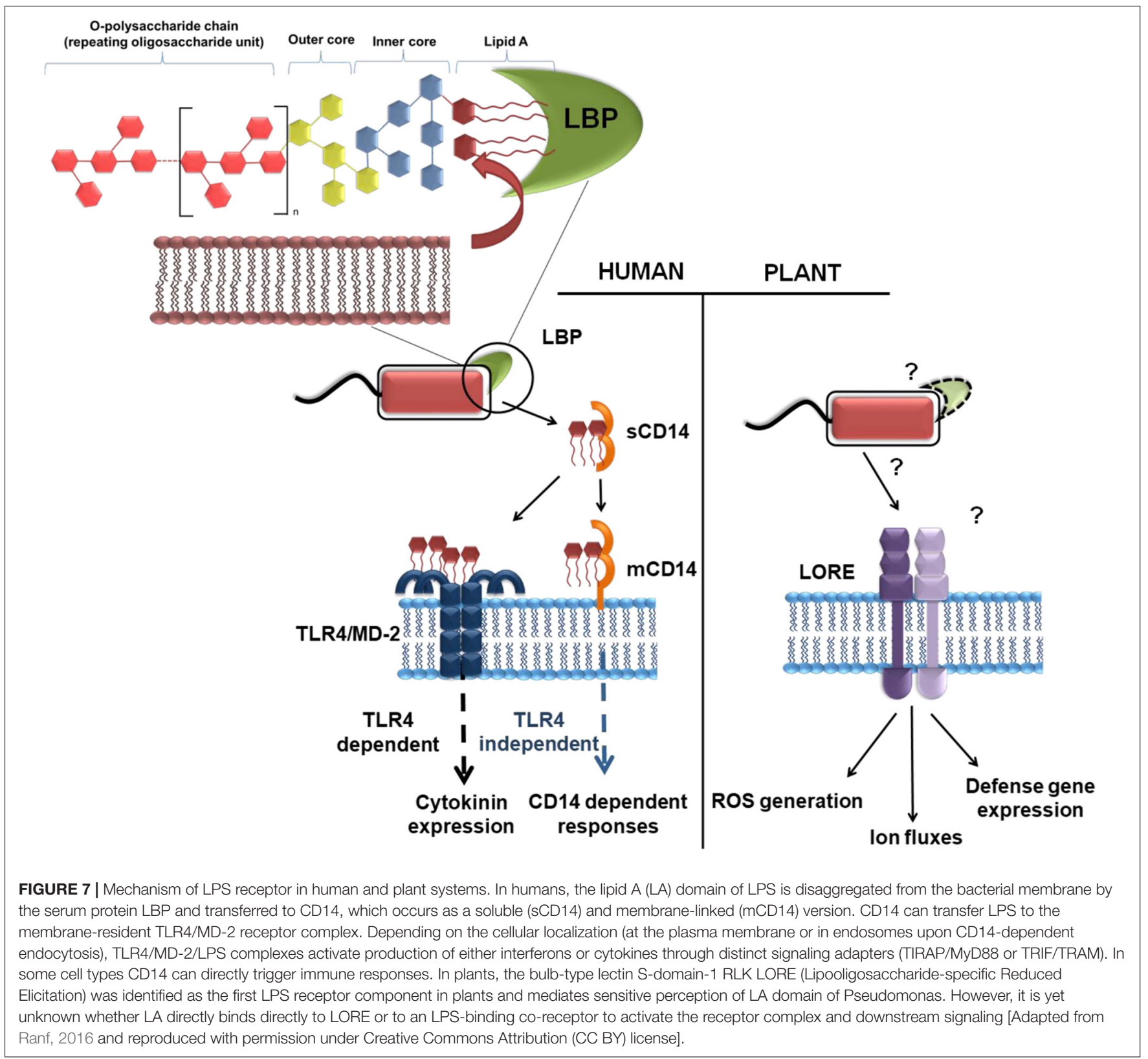


inference from mammalians LPS signaling, it is currently believed that LORE undergoes dimerization during LPS perception. However, it is still not clear if any other plant defense modulators facilitate the transfer of the LA or facilitate LPS recognition and signaling in a LORE-independent manner.

Galactolipids, which are primarily composed of monogalactosyldiacylglycerol (MGDG) and digalactosyldiacylglycerol (DGDG), are important plant glycerolipids, known for their role in mediating in systemic acquired resistance (SAR) based plant defenses. It was seen that Arabidopsis mgd1 mutant which is deficient in MGDG synthesis and the $d g d 1$ mutant, deficient in DGDG synthesis could not mount a SAR mediated defense response, when challenged with a secondary infection of the virulent pathogen $P$. syringae pv. maculicola after they were primed with the avirulent pathogen $P$. syringae pv. Tomato (Chaturvedi et al., 2008; Gao et al., 2014). This provides a strong evidence regarding the role of MGDG and DGDG in establishing SAR during pathogen attack; however, the complete pathway remains to be elucidated.

Phosphoinositol sphingolipids and glucosylceramides (GlcCer) are another group of glycosylated lipids found in fungi that feature a characteristic C-9 methyl group present on the long chain fatty acid base (Warnecke and Heinz, 2003). These fungal GlcCer behave as elicitors that induce plant defense responses like phytoalexin production and PR protein synthesis, when sprayed on to rice (Umemura et al., 2000).

Natural rhamnolipids produced by Pseudomonas aeruginosa have been shown to induce defense responses in grapevines, tobacco, and Arabidopsis cells via oxidative burst, ROS production, and inducing systemic acquired resistance (Varnier et al., 2009; Sanchez et al., 2012). In this context, natural rhamnose based glycolipids were synthesized enzymatically to use as elicitors of defense response and were found to induce extracellular ROS production when tested on tobacco cells (Nasir et al., 2017).

\section{CONCLUSION}

Our current understanding of the roles that carbohydrates play in PAMP based defense priming in plants remains fragmented. Although the potential role of glycans as elicitors of plant defense signaling cascades has been identified as an important aspect, there remains a huge information gap when compared to what we currently understand about proteinaceous receptors of these glycan elicitors. The likely reason for this is the complexity of carbohydrate structures and the fact that the techniques used to analyze glycans lag behind those for protein and gene analysis. Improvements in oligosaccharide extraction, purification and identification techniques are beginning to enable studies using

\section{REFERENCES}

Adachi, Y., Ishii, T., Ikeda, Y., Hoshino, A., Tamura, H., Aketagawa, J., et al. (2004). Characterization of $\beta$-glucan recognition site on C-type lectin, dectin 1. Infect. Immun. 72, 4159-4171. doi: 10.1128/IAI.72.7.4159 more specific glycan species rather than crude extracts containing polydisperse carbohydrate species. The understanding of the roles played by carbohydrates in plant-pathogen interactions falls behind knowledge in human-pathogen interactions, which has attracted attention due to the implications in medicine development and disease treatment. It is only recently that we have begun to realize the importance carbohydrates have in plant protection strategies and appreciate the potential that carbohydrates have as specific intervention technologies.

In their natural habitat, plants are exposed to a wide variety of symbiotic and pathogenic microflora at any given time, which paves the way for a novel and extensive area of research to investigate the controlled and diversified signaling cascades generated within plants in response to simultaneous attack from different microbes. Plant genomes encode a large number of RLKs, RLPs, and lectins; biochemical and structural studies on these receptors will lead to better knowledge of their workings and allow identification of the most suitable oligosaccharide candidates.

Coming to the concept of sustainable agriculture, there is potential to use oligosaccharides for crop protection, to induce pathogen resistance and prime plants for microbial attack. The use of biodegradable, environmentally friendly glycans and glycan mimics will help to replace the conventionally used chemicals with safer alternatives. This will enable more sustainable agriculture and help avoid major crop losses, allowing better food security, given mankind's growing demand for food quality and quantity.

\section{AUTHOR CONTRIBUTIONS}

CC, EK, and MR conceived the idea and prepared the draft of the manuscript. RF supervised the development of topics for discussion and edited the draft manuscript.

\section{FUNDING}

This work was supported by a Biotechnology and Biological Sciences Research Council (BBSRC, United Kingdom) Institute Strategic Program Grant (MFN)(BB/P012523/1) to the John Innes Centre. EK acknowledges DBT, Government of India for the Overseas Associateship fellowship which was availed at the John Innes Centre, at RF's laboratory (BT/20/NE/2011). CC would like to acknowledge DST, Government of India for her DST INSPIRE Junior Research Fellowship (IF150964). MR is supported by BBSRC-ERA-CAPS grant (BB/N010272/1) to RF. $\mathrm{EK}$ and CC wish to acknowledge DBT, Government of India, for the Twinning Research Grant (Grant No. BT/427/NE/TBP/2011). 
Alexander, C., and Rietschel, E. T. (2001). Invited review: bacterial lipopolysaccharides and innate immunity. J. Endotoxin Res. 7, 167-202. doi: $10.1177 / 09680519010070030101$

An, Q. D., Zhang, G. L., Wu, H. T., Zhang, Z. C., Zheng, G. S., Luan, L., et al. (2009). Alginate-deriving oligosaccharide production by alginase from newly isolated Flavobacterium sp. LXA and its potential application in protection against pathogens. J. Appl. Microbiol. 106, 161-170. doi: 10.1111/j.1365-2672. 2008.03988.x

Anderson, J. A., Gipmans, M., Hurst, S., Layton, R., Nehra, N., Pickett, J., et al. (2016). Emerging agricultural biotechnologies for sustainable agriculture and food security. J. Agric. Food Chem. 64, 383-393. doi: 10.1021/acs.jafc.5b04543

Andre, S., Siebert, H. C., Nishiguchi, M., Tazaki, K., and Gabius, H. J. (2005) Evidence for lectin activity of a plant receptor-like protein kinase by application of neoglycoproteins and bioinformatic algorithms. Biochim. Biophys. Acta 1725, 222-232. doi: 10.1016/j.bbagen.2005.04.004

Ayers, A. R., Ebel, J., Valent, B., and Albersheim, P. (1976). Host-pathogen interactions: X. Fractionation and biological activity of an elicitor isolated from the mycelial walls of Phytophthora megasperma var. sojae. Plant Physiol. 57, 760-765. doi: 10.1104/pp.57.5.760

Aziz, A., Gauthier, A., Bézier, A., Poinssot, B., Joubert, J. M., and Pugin, A. (2007). Elicitor and resistance-inducing activities of $\beta-1,4$ cellodextrins in grapevine, comparison with $\beta-1,3$ glucans and $\alpha-1,4$ oligogalacturonides. J. Exp. Bot. 58, 1463-1472. doi: 10.1093/jxb/erm008

Aziz, A., Poinssot, B., Daire, X., Adrian, M., Bézier, A., Lambert, B., et al. (2003). Laminarin elicits defense responses in grapevine and induces protection against Botrytis cinerea and Plasmopara viticola. Mol. Plant Microbe Interact. 16, 1118-1128. doi: 10.1094/MPMI.2003.16.12.1118

Baena-Gonzalez, E. (2010). Energy signaling in the regulation of gene expression during stress. Mol. Plant 3, 300-313. doi: $10.1093 / \mathrm{mp} / \mathrm{ssp} 113$

Beutler, B., Du, X., and Poltorak, A. (2001). Identification of Toll-like receptor 4 (Tlr4) as the sole conduit for LPS signal transduction: genetic, and evolutionary studies. J. Endotoxin Res. 7, 277-280. doi: 10.1177/09680519010070040901

Boller, T., and Felix, G. (2009). A renaissance of elicitors: perception of microbeassociated molecular patterns and danger signals by pattern-recognition receptors. Annu. Rev. Plant Biol. 60, 379-406. doi: 10.1146/annurev.arplant.57. 032905.105346

Bolouri Moghaddam, M. R., and Van den Ende, W. (2012). Sugars and plant innate immunity. J. Exp. Bot. 63, 3989-3998. doi: 10.1093/jxb/ers129

Boudart, G., Charpentier, M., Lafitte, C., Martinez, Y., Jauneau, A., Gaulin, E., et al. (2003). Elicitor activity of a fungal endopolygalacturonase in tobacco requires a functional catalytic site and cell wall localization. Plant Physiol. 131, 93-101. doi: 10.1104/pp.011585

Brown, G. D., and Gordon, S. (2003). Fungal $\beta$-glucans and mammalian immunity. Immunity 19, 311-315. doi: 10.1016/S1074-7613(03)00233-4

Brown, J., O'Callaghan, C. A., Marshall, A. S., Gilbert, R. J., Siebold, C., Gordon, S., et al. (2007). Structure of the fungal $\beta$-glucan-binding immune receptor dectin-1: implications for function. Protein Sci. 1, 1042-1052. doi: 10.1110/ps. 072791207

Burkhanova, G. F., Yarullina, L. G., and Maksimov, I. V. (2007). The control of wheat defense responses during infection with Bipolaris sorokiniana by chitooligosaccharides. Russ. J. Plant Physiol. 54, 104-110. doi: 10.1134/ S1021443707010153

Caillot, S., Rat, S., Tavernier, M. L., Michaud, P., Kovensky, J., Wadouachi, A., et al. (2012). Native and sulfated oligoglucuronans as elicitors of defencerelated responses inducing protection against Botrytis cinerea of Vitis vinifera. Carbohydr. Polym. 87, 1728-1736. doi: 10.1016/j.carbpol.2011.09.084

Calmes, B., Guillemette, T., Teyssier, L., Siegler, B., Pigné, S., Landreau, A., et al. (2013). Role of mannitol metabolism in the pathogenicity of the necrotrophic fungus Alternaria brassicicola. Front. Plant Sci. 4:131. doi: 10.3389/fpls.2013. 00131

Chaturvedi, R., Krothapalli, K., Makandar, R., Nandi, A., Sparks, A., Roth, M., et al. (2008). Plastid omega3-fatty acid desaturase-dependent accumulation of a systemic acquired resistance inducing activity in petiole exudates of Arabidopsis thaliana is independent of jasmonic acid. Plant J. 54, 106-117. doi: 10.1111/j. 1365-313X.2007.03400.x

Cheong, J. J., and Hahn, M. G. (1991). A specific, high-affinity binding site for the hepta-beta-glucoside elicitor exists in soybean membranes. Plant Cell 3, 137-147. doi: 10.1105/tpc.3.2.137
Cho, J. I., Ryoo, N., Eom, J. S., Lee, D. W., Kim, H. B., Jeong, S. W., et al. (2009). Role of the rice hexokinases OsHXK5 and OsHXK6 as glucose sensors. Plant Physiol. 149, 745-759. doi: 10.1104/pp.108.131227

Choi, J., Tanaka, K., Cao, Y., Qi, Y., Qiu, J., Liang, Y., et al. (2014). Identification of a plant receptor for extracellular ATP. Science 343, 290-294. doi: 10.1126/ science.343.6168.290

Conrath, U., Domard, A., and Kauss, H. (1989). Chitosan-elicited synthesis of callose and of coumarin derivatives in parsley cell suspension cultures. Plant Cell Rep. 8, 152-155. doi: 10.1007/BF00716829

Cosio, E. G., Feger, M., Miller, C. J., Antelo, L., and Ebel, J. (1996). High-affinity binding of fungal $\beta$-glucan elicitors to cell membranes of species of the plant family Fabaceae. Planta 200, 92-99. doi: 10.1007/BF00196654

Cote, F., Roberts, K. A., and Hahn, M. G. (2000). Identification of highaffinity binding sites for the hepta- $\beta$-glucoside elicitor in membranes of the model legumes Medicago truncatula and Lotus japonicus. Planta 211, 596-605. doi: $10.1007 / \mathrm{s} 004250000325$

De Azevedo Souza, C., Li, S., Lin, A. Z., Boutrot, F., Grossmann, G., Zipfel, C., et al. (2017). Cellulose-derived oligomers act as damage-associated molecular patterns and trigger defense-like responses. Plant Physiol. 173, 2383-2398. doi: $10.1104 / p p .16 .01680$

De Lorenzo, G., and Ferrari, S. (2002). Polygalacturonase-inhibiting proteins in defense against phytopathogenic fungi. Curr. Opin. Plant Biol. 5, 295-299. doi: 10.1016/S1369-5266(02)00271-6

Drummond, R. A., and Brown, G. D. (2011). The role of Dectin-1 in the host defence against fungal infections. Curr. Opin. Microbiol. 14, 392-399. doi: 10.1016/j.mib.2011.07.001

Ebel, J., Ayers, A. R., and Albersheim, P. (1976). Response of suspension-cultured soybean cells to the elicitor isolated from Phytophthora megasperma var. sojae, a fungal pathogen of soybeans. Plant Physiol. 57, 775-779. doi: 10.1104/pp.57. 5.775

Egusa, M., Matsui, H., Urakami, T., Okuda, S., Ifuku, S., Nakagami, H., et al. (2015). Chitin nanofiber elucidates the elicitor activity of polymeric chitin in plants. Front. Plant Sci. 6:1098. doi: 10.3389/fpls.2015.01098

Espino, J. J., Gutiérrez-Sánchez, G., Brito, N., Shah, P., Orlando, R., and González, C. (2010). The Botrytis cinerea early secretome. Proteomics 10, 3020-3034. doi: 10.1002/pmic.201000037

Farmer, E. E., Moloshok, T. D., Saxton, M. J., and Ryan, C. A. (1991). Oligosaccharide signaling in plants. Specificity of oligouronide-enhanced plasma membrane protein phosphorylation. J. Biol. Chem. 266, 3140-3145. doi: 10.1146/annurev.cellbio.3.1.295

Fesel, P. H., and Zuccaro, A. (2016). $\beta$-glucan: crucial component of the fungal cell wall and elusive MAMP in plants. Fungal Genet. Biol. 90, 53-60. doi: 10.1016/j.fgb.2015.12.004

Formela, M., Samardakiewicz, S., Marczak, Ł., Nowak, W., Narożna, D., Bednarski, W., et al. (2014). Effects of endogenous signals and Fusarium oxysporum on the mechanism regulating genistein synthesis and accumulation in yellow lupine and their impact on plant cell cytoskeleton. Molecules 19, 13392-13421. doi: 10.3390/molecules190913392

Frias, M., González, M., González, C., and Brito, N. (2016). BcIEB1, a Botrytis cinerea secreted protein, elicits a defense response in plants. Plant Sci. 250, 115-124. doi: 10.1016/j.plantsci.2016.06.009

Fu, Y., Yin, H., Wang, W., Wang, M., Zhang, H., Zhao, X., et al. (2011). $\beta$-1,3-glucan with different degree of polymerization induced different defense responses in tobacco. Carbohydr. Polym. 86, 774-782. doi: 10.1016/j.carbpol. 2011.05.022

Fuechtbauer, W., Yunusov, T., Bozsoki, Z., Gavrin, A., James, E. K., Stougaard, J., et al. (2018). LYS12 LysM receptor decelerates Phytophthora palmivora disease progression in Lotus japonicus. Plant J. 93, 297-310. doi: 10.1111/tpj. 13785

Galletti, R., Denoux, C., Gambetta, S., Dewdney, J., Ausubel, F. M., De Lorenzo, G., et al. (2008). The AtrbohD-mediated oxidative burst elicited by oligogalacturonides in Arabidopsis is dispensable for the activation of defense responses effective against Botrytis cinerea. Plant Physiol. 148, 1695-1706. doi: $10.1104 /$ pp.108.127845

Gao, Q. M., Yu, K., Xia, Y., Shine, M. B., Wang, C., Navarre, D., et al. (2014). Mono-and digalactosyldiacylglycerol lipids function nonredundantly to regulate systemic acquired resistance in plants. Cell Rep. 9, 1681-1691. doi: 10.1016/j.celrep.2014.10.069 
Gomez-Ariza, J., Campo, S., Rufat, M., Estopà, M., Messeguer, J., Segundo, B. S., et al. (2007). Sucrose-mediated priming of plant defense responses and broadspectrum disease resistance by overexpression of the maize pathogenesisrelated PRms protein in rice plants. Mol. Plant Microbe Interact. 20, 832-842. doi: 10.1094/MPMI-20-7-0832

Gonzalez, A., Castro, J., Vera, J., and Moenne, A. (2013). Seaweed oligosaccharides stimulate plant growth by enhancing carbon and nitrogen assimilation, basal metabolism, and cell division. J. Plant Growth Regul. 32, 443-448. doi: 10.1007/ s00344-012-9309-1

Gonzalez, M., Brito, N., and Gonzalez, C. (2012). High abundance of Serine/Threonine-rich regions predicted to be hyper-O-glycosylated in the secretory proteins coded by eight fungal genomes. BMC Microbiol. 12:213. doi: 10.1186/1471-2180-12-21

Gonzalez, M., Brito, N., and Gonzalez, C. (2014). Identification of glycoproteins secreted by wild-type Botrytis cinerea and by protein O-mannosyltransferase mutants. BMC Microbiol. 14:254. doi: 10.1186/s12866-014-0254-y

Gonzalez, M., Brito, N., and Gonzalez, C. (2017). The Botrytis cinerea elicitor protein BcIEB1 interacts with the tobacco PR5-family protein osmotin and protects the fungus against its antifungal activity. New Phytol. 215, 397-410. doi: $10.1111 /$ nph. 14588

Gouget, A., Senchou, V., Govers, F., Sanson, A., Barre, A., Rouge, P., et al. (2006). Lectin receptor kinases participate in protein-protein interactions to mediate plasma membrane-cell wall adhesions in Arabidopsis. Plant Physiol. 140, 81-90. doi: 10.1104/pp.105.066464

Greeff, C., Roux, M., Mundy, J., and Petersen, M. (2012). Receptor-like kinase complexes in plant innate immunity. Front. Plant Sci. 3:209. doi: 10.3389/fpls. 2012.00209

Hopke, A., Brown, A. J., Hall, R. A., and Wheeler, R. T. (2018). Dynamic fungal cell wall architecture in stress adaptation and immune evasion. Trends Microbiol. 26, 284-295. doi: 10.1016/j.tim.2018.01.007

Hulsmans, S., Rodriguez, M., De Coninck, B., and Rolland, F. (2016). The SnRK1 energy sensor in plant biotic interactions. Trends Plant Sci. 21, 648-661. doi: 10.1016/j.tplants.2016.04.008

Inui, H., Yamaguchi, Y., and Hirano, S. (1997). Elicitor actions of $\mathrm{N}$-acetylchitooligosaccharides and laminarioligosaccharides for chitinase and L-phenylalanine ammonia-lyase induction in rice suspension culture. Biosci. Biotechnol. Biochem. 61, 975-978. doi: 10.1271/bbb.61.975

Ishibashi, Y., Yamaguchi, H., Yuasa, T., Iwaya-Inoue, M., Arima, S., and Zheng, S. H. (2011). Hydrogen peroxide spraying alleviates drought stress in soybean plants. J. Plant Physiol. 168, 1562-1567. doi: 10.1016/j.jplph.2011.02.003

Jennings, D. B., Daub, M. E., Pharr, D. M., and Williamson, J. D. (2002). Constitutive expression of a celery mannitol dehydrogenase in tobacco enhances resistance to the mannitol-secreting fungal pathogen Alternaria alternata. Plant J. 32, 41-49. doi: 10.1046/j.1365-313X.2001.01399.x

Jennings, D. H. (1985). Polyol metabolism in fungi. Adv. Microb. Physiol. 25, 149-193. doi: 10.1016/S0065-2911(08)60292-1

Jones, O. A., Maguire, M. L., Griffin, J. L., Jung, Y. H., Shibato, J., Rakwal, R., et al. (2011). Using metabolic profiling to assess plant-pathogen interactions: an example using rice (Oryza sativa) and the blast pathogen Magnaporthe grisea. Eur. J. Plant Pathol. 129, 539-554. doi: 10.1007/s10658-0109718-6

Joosten, M. H., Hendrickx, L. J., and De Wit, P. J. (1990). Carbohydrate composition of apoplastic fluids isolated from tomato leaves inoculated with virulent or avirulent races of Cladosporium fulvum (syn. Fulvia fulva). Neth. J. Plant Pathol. 96, 103-112. doi: 10.1007/BF02005134

Juchaux-Cachau, M., Landouar-Arsivaud, L., Pichaut, J. P., Campion, C., Porcheron, B., Jeauffre, J., et al. (2007). Characterization of AgMaT2, a plasma membrane mannitol transporter from celery, expressed in phloem cells, including phloem parenchyma cells. Plant Physiol. 145, 62-74. doi: 10.1104/pp. 107.103143

Kim, M., Lim, J. H., Ahn, C. S., Park, K., Kim, G. T., Kim, W. T., et al. (2006). Mitochondria-associated hexokinases play a role in the control of programmed cell death in Nicotiana benthamiana. Plant Cell 18, 2341-2355. doi: 10.1105/tpc. 106.041509

Kim, M. S., Cho, S. M., Kang, E. Y., Im, Y. J., Hwangbo, H., Kim, Y. C., et al. (2008). Galactinol is a signaling component of the induced systemic resistance caused by Pseudomonas chlororaphis O6 root colonization. Mol. Plant Microbe Interact. 21, 1643-1653. doi: 10.1094/MPMI-21-12-1643
Kishimoto, K., Kouzai, Y., Kaku, H., Shibuya, N., Minami, E., and Nishizawa, Y. (2010). Perception of the chitin oligosaccharides contributes to disease resistance to blast fungus Magnaporthe oryzae in rice. Plant J. 64, 343-354. doi: 10.1111/j.1365-313X.2010.04328.x

Klarzynski, O., Descamps, V., Plesse, B., Yvin, J. C., Kloareg, B., and Fritig, B. (2003). Sulfated fucan oligosaccharides elicit defense responses in tobacco and local and systemic resistance against tobacco mosaic virus. Mol. Plant Microbe Interact. 16, 115-122. doi: 10.1094/MPMI.2003.16.2.115

Klarzynski, O., Plesse, B., Joubert, J. M., Yvin, J. C., Kopp, M., Kloareg, B., et al. (2000). Linear $\beta-1,3$ glucans are elicitors of defense responses in tobacco. Plant Physiol. 124, 1027-1038. doi: 10.1104/pp.124.3.1027

Kohle, H., Jeblick, W., Poten, F., Blaschek, W., and Kauss, H. (1985). Chitosanelicited callose synthesis in soybean cells as a $\mathrm{Ca}^{2+}$-dependent process. Plant Physiol. 77, 544-551. doi: 10.1104/pp.77.3.544

Kombrink, E., and Somssich, I. E. (1995). Defense responses of plants to pathogens. Adv. Bot. Res. 21, 1-34. doi: 10.1016/S0065-2296(08)60007-5

Lannoo, N., Van Damme, E. J., Albenne, C., and Jamet, E. (2014). Plant glycobiology - a diverse world of lectins, glycoproteins, glycolipids and glycans. Front. Plant Sci. 5:604. doi: 10.3389/fpls.2014.00604

Levitz, S. M. (2010). Innate recognition of fungal cell walls. PLoS Pathog. 6:e1000758. doi: 10.1371/journal.ppat.1000758

Melida, H., Sopena-Torres, S., Bacete, L., Garrido-Arandia, M., Jordá, L., Lopez, G., et al. (2018). Non-branched $\beta$-1,3-glucan oligosaccharides trigger immune responses in Arabidopsis. Plant J. 93, 34-49. doi: 10.1111/tpj.13755

Menard, R., Alban, S., de Ruffray, P., Jamois, F., Franz, G., Fritig, B., et al. (2004). $\beta-1,3$ glucan sulfate, but not $\beta-1,3$ glucan, induces the salicylic acid signaling pathway in Tobacco and Arabidopsis. Plant Cell 1, 3020-3032. doi: 10.1105/ tpc. 104.024968

Miya, A., Albert, P., Shinya, T., Desaki, Y., Ichimura, K., Shirasu, K., et al. (2007). CERK1, a LysM receptor kinase, is essential for chitin elicitor signaling in Arabidopsis. Proc. Natl. Acad. Sci. U.S.A. 104, 19613-19618. doi: 10.1073/pnas. 0705147104

Moore, B., Zhou, L., Rolland, F., Hall, Q., Cheng, W. H., Liu, Y. X., et al. (2003). Role of the Arabidopsis glucose sensor HXK1 in nutrient, light, and hormonal signaling. Science 300, 332-336. doi: 10.1126/science.1080585

Morkunas, I., Marczak, L., Stachowiak, J., and Stobiecki, M. (2005). Sucroseinduced lupine defense against Fusarium oxysporum: sucrose-stimulated accumulation of isoflavonoids as a defense response of lupine to Fusarium oxysporum. Plant Physiol. Biochem. 43, 363-373. doi: 10.1016/j.plaphy.2005. 02.011

Morkunas, I., and Ratajczak, L. (2014). The role of sugar signaling in plant defense responses against fungal pathogens. Acta Physiol. Plant. 36, 1607-1619. doi: $10.1007 / \mathrm{s} 11738-014-1559-\mathrm{z}$

Muchembled, J., Sahraoui, A. L. H., Grandmougin-Ferjani, A., and Sancholle, M. (2006). Changes in lipid composition of Blumeria graminis f.sp. tritici conidia produced on wheat leaves treated with heptanoyl salicylic acid. Phytochemistry 67, 1104-1109. doi: 10.1016/j.phytochem.2006.02.025

Nasir, M. N., Lins, L., Crowet, J. M., Ongena, M., Dorey, S., Dhondt-Cordelier, S., et al. (2017). Differential interaction of synthetic glycolipids with biomimetic plasma membrane lipids correlates with the plant biological response. Langmuir 33, 9979-9987. doi: 10.1021/acs.langmuir.7b01264

Navazio, L., Moscatiello, R., Bellincampi, D., Baldan, B., Meggio, F., Brini, M., et al. (2002). The role of calcium in oligogalacturonide-activated signalling in soybean cells. Planta 215, 596-605. doi: 10.1007/s00425-0020776-7

Nishizawa, A., Yabuta, Y., and Shigeoka, S. (2008). Galactinol and raffinose constitute a novel function to protect plants from oxidative damage. Plant Physiol. 147, 1251-1263. doi: 10.1104/pp.108.122465

Noiraud, N., Maurousset, L., and Lemoine, R. (2001). Transport of polyols in higher plants. Plant Physiol. Biochem. 39, 717-728. doi: 10.1016/S09819428(01)01292-X

Nunes, C., Primavesi, L. F., Patel, M. K., Martinez-Barajas, E., Powers, S. J., Sagar, R., et al. (2013). Inhibition of SnRK1 by metabolites: tissue-dependent effects and cooperative inhibition by glucose 1-phosphate in combination with trehalose 6-phosphate. Plant Physiol. Biochem. 63, 89-98. doi: 10.1016/j.plaphy. 2012.11.011

Nurnberger, T., Nennstiel, D., Jabs, T., Sacks, W. R., Hahlbrock, K., and Scheel, D. (1994). High affinity binding of a fungal oligopeptide elicitor to parsley plasma 
membranes triggers multiple defense responses. Cell 78, 449-460. doi: 10.1016/ 0092-8674(94)90423-5

Okmen, B., and Doehlemann, G. (2016). Clash between the borders: spotlight on apoplastic processes in plant-microbe interactions. New Phytol. 212, 799-801. doi: $10.1111 /$ nph.14311

Patel, T. K., and Williamson, J. D. (2016). Mannitol in plants, fungi, and plantfungal interactions. Trends Plant Sci. 21, 486-497. doi: 10.1016/j.tplants.2016. 01.006

Petrov, V., Hille, J., Mueller-Roeber, B., and Gechev, T. S. (2015). ROS-mediated abiotic stress-induced programmed cell death in plants. Front. Plant Sci. 6:69. doi: 10.3389/fpls.2015.00069

Ranf, S. (2016). Immune sensing of lipopolysaccharide in plants and animals: same but different. PLoS Pathog. 12:e1005596. doi: 10.1371/journal.ppat.1005596

Ranf, S., Gisch, N., Schäffer, M., Illig, T., Westphal, L., Knirel, Y. A., et al. (2015). A lectin S-domain receptor kinase mediates lipopolysaccharide sensing in Arabidopsis thaliana. Nat. Immunol. 16, 426-433. doi: 10.1038/ni.3124

Reignault, P. H., Cogan, A., Muchembled, J., Lounes-Hadj Sahraoui, A., Durand, R., and Sancholle, M. (2001). Trehalose induces resistance to powdery mildew in wheat. New Phytol. 149, 519-529. doi: 10.1046/j.1469-8137.2001. 00035.x

Rojas, C. M., Senthil-Kumar, M., Tzin, V., and Mysore, K. (2014). Regulation of primary plant metabolism during plant-pathogen interactions and its contribution to plant defense. Front. Plant Sci. 5:17. doi: 10.3389/fpls.2014. 00017

Rovenich, H., Zuccaro, A., and Thomma, B. P. (2016). Convergent evolution of filamentous microbes towards evasion of glycan-triggered immunity. New Phytol. 212, 896-901. doi: 10.1111/nph.14064

Sanchez, L., Courteaux, B., Hubert, J., Kauffmann, S., Renault, J.-H., Clément, C., et al. (2012). Rhamnolipids elicit defense responses and induce disease resistance against biotrophic, hemibiotrophic, and necrotrophic pathogens that require different signaling pathways in Arabidopsis and highlight a central role for salicylic acid. Plant Physiol. 160, 1630-1641. doi: 10.1104/pp.112.201913

Savvides, A., Ali, S., Tester, M., and Fotopoulos, V. (2016). Chemical priming of plants against multiple abiotic stresses: mission possible? Trends Plant Sci. 21, 329-340. doi: 10.1016/j.tplants.2015.11.003

Sengupta, S., Mukherjee, S., Basak, P., and Majumder, A. L. (2015). Significance of galactinol and raffinose family oligosaccharide synthesis in plants. Front. Plant Sci. 6:656. doi: 10.3389/fpls.2015.00656

Sharp, J. K., Valent, B., and Albersheim, P. (1984a). Purification and partial characterization of a beta-glucan fragment that elicits phytoalexin accumulation in soybean. J. Biol. Chem. 259, 11312-11320.

Sharp, J. K., Valent, B., and Albersheim, P. (1984b). The primary structures of one elicitor active and seven elicitor-inactive hexa (beta-D-glucopyranosyl)-Dglucitols isolated from the mycelial walls of Phytophthora megasperma f. sp. glycinea. J. Biol. Chem. 259, 11321-11336.

Shibuya, N., and Minami, E. (2001). Oligosaccharide signalling for defence responses in plant. Physiol. Mol. Plant Pathol. 59, 223-233. doi: 10.1006/pmpp. 2001.0364

Silipo, A., Erbs, G., Shinya, T., Dow, J. M., Parrilli, M., Lanzetta, R., et al. (2010). Glycoconjugates as elicitors or suppressors of plant innate immunity. Glycobiology 20, 406-419. doi: 10.1093/glycob/cwp201

Singh, P., and Zimmerli, L. (2013). Lectin receptor kinases in plant innate immunity. Front. Plant Sci. 4:124. doi: 10.3389/fpls.2013.00124

Sobhy, I. S., Erb, M., Lou, Y., and Turlings, T. C. (2014). The prospect of applying chemical elicitors and plant strengtheners to enhance the biological control of crop pests. Philos. Trans. R. Soc. B Biol. Sci. 369:20120283. doi: 10.1098/rstb. 2012.0283

Solomon, P. S., Waters, O. D., and Oliver, R. P. (2007). Decoding the mannitol enigma in filamentous fungi. Trends Microbiol. 15, 257-262. doi: 10.1016/j.tim. 2007.04.002

Sun, J., Miller, J. B., Granqvist, E., Wiley-Kalil, A., Gobbato, E., Maillet, F., et al. (2015). Activation of symbiosis signaling by arbuscular mycorrhizal fungi in legumes and rice. Plant Cell 27, 823-838. doi: 10.1105/tpc.114.131326

Tan, Y., and Kagan, J. C. (2014). A cross-disciplinary perspective on the innate immune responses to bacterial lipopolysaccharide. Mol. Cell 54, 212-223. doi: 10.1016/j.molcel.2014.03.012

Tanaka, S., Ichikawa, A., Yamada, K., Tsuji, G., Nishiuchi, T., Mori, M., et al. (2010). HvCEBiP, a gene homologous to rice chitin receptor CEBiP, contributes to basal resistance of barley to Magnaporthe oryzae. BMC Plant Biol. 10:288. doi: 10.1186/1471-2229-10-288

Tauzin, A. S., and Giardina, T. (2014). Sucrose and invertases, a part of the plant defense response to the biotic stresses. Front. Plant Sci. 5:293. doi: 10.3389/fpls. 2014.00293

Trouvelot, S., Héloir, M. C., Poinssot, B., Gauthier, A., Paris, F., Guillier, C., et al. (2014). Carbohydrates in plant immunity and plant protection: roles and potential application as foliar sprays. Front. Plant Sci. 5:592. doi: 10.3389/fpls. 2014.00592

Umemura, K., Ogawa, N., Yamauchi, T., Iwata, M., Shimura, M., and Koga, J. (2000). Cerebroside elicitors found in diverse phytopathogens activate defense responses in rice plants. Plant Cell Physiol. 41, 676-683. doi: 10.1093/pcp/41. 6.676

Varnier, A. L., Sanchez, L., Vatsa, P., Boudesocque, L., Garcia-Brugger, A., Rabenoelina, L., et al. (2009). Bacterial rhamnolipids are novel MAMPs conferring resistance to Botrytis cinerea in grapevine. Plant Cell Environ. 32, 178-193. doi: 10.1111/j.1365-3040.2008.01911.x

Vélëz, H., Glassbrook, N. J., and Daub, M. E. (2007). Mannitol metabolism in the phytopathogenic fungus Alternaria alternata. Fungal Genet. Biol. 44, 258-268. doi: 10.1016/j.fgb.2006.09.008

Vidal, S., Eriksson, A. R. B., Montesano, M., Denecke, J., and Palva, E. T. (1998). Cell wall-degrading enzymes from Erwinia carotovora cooperate in the salicylic acid independent induction of a plant defense response. Mol. Plant Microbe Interact. 11, 23-32. doi: 10.1094/MPMI.1998.11.1.23

Vorholter, F. J., Wiggerich, H. G., Scheidle, H., Sidhu, V. K., Mrozek, K., Küster, H., et al. (2012). Involvement of bacterial tonb-dependent signaling in the generation of an oligogalacturonide damage-associated molecular pattern from plant cell walls exposed to Xanthomonas campestris pv. campestris pectate lyases. BMC Microbiol. 12:239. doi: 10.1186/1471-2180-12-239

Wang, Y., and Bouwmeester, K. (2017). L-type lectin receptor kinases: new forces in plant immunity. PLoS Pathog. 13:e1006433. doi: 10.1371/journal.ppat.1006433

Warnecke, D., and Heinz, E. (2003). Recently discovered functions of glucosylceramides in plants and fungi. Cell. Mol. Life Sci. 60, 919-941. doi: 10.1007/s00018-003-2243-4

Weidenbach, D., Esch, L., Moller, C., Hensel, G., Kumlehn, J., Hofle, C., et al. (2016). Polarized defense against fungal pathogens is mediated by the jacalinrelated lectin domain of modular Poaceae-specific proteins. Mol. Plant 9, 514-527. doi: 10.1016/j.molp.2015.12.009

Whitfield, C., and Trent, M. S. (2014). Biosynthesis and export of bacterial lipopolysaccharides. Annu. Rev. Biochem. 83, 99-128. doi: 10.1146/annurevbiochem-060713-035600

Williamson, J. D., Desai, A., Krasnyanski, S. F., Ding, F., Guo, W. W., Nguyen, T. T., et al. (2013). Overexpression of mannitol dehydrogenase in zonal geranium confers increased resistance to the mannitol secreting fungal pathogen Botrytis cinerea. Plant Cell Tissue Organ Cult. 115, 367-375. doi: 10.1007/s11240-0130368-1

Xiao, W., Sheen, J., and Jang, J. C. (2000). The role of hexokinase in plant sugar signal transduction and growth and development. Plant Mol. Biol. 44, 451-461. doi: 10.1023/A:1026501430422

Yamada, A., Shibuya, N., Kodama, O., and Akatsuka, T. (1993). Induction of phytoalexin formation in suspension-cultured rice cells by N-acetylchitooligosaccharides. Biosci. Biotechnol. Biochem. 57, 405-409. doi: 10.1271/bbb.57.405

Yamaguchi, K., Yamada, K., Ishikawa, K., Yoshimura, S., Hayashi, N., Uchihashi, K., et al. (2013). A receptor-like cytoplasmic kinase targeted by a plant pathogen effector is directly phosphorylated by the chitin receptor and mediates rice immunity. Cell Host Microbe 13, 347-357. doi: 10.1016/j.chom.2013. 02.007

Zhang, S., Tang, W., Jiang, L., Hou, Y., Yang, F., Chen, W., et al. (2015). Elicitor activity of algino-oligosaccharide and its potential application in protection of rice plant (Oryza sativa L.) against Magnaporthe grisea. Biotechnol. Biotechnol. Equip. 29, 646-652. doi: 10.1080/13102818.2015.1039943

Zhang, Y., Primavesi, L. F., Jhurreea, D., Andralojc, P. J., Mitchell, R. A., Powers, S. J., et al. (2009). Inhibition of SNF1-related protein kinasel activity and regulation of metabolic pathways by trehalose-6-phosphate. Plant Physiol. 149, 1860-1871. doi: 10.1104/pp.108.133934

Zhang, Y., Zhang, Y., Qiu, D., Zeng, H., Guo, L., and Yang, X. (2015). BcGs1, a glycoprotein from Botrytis cinerea, elicits defence response and improves 
disease resistance in host plants. Biochem. Biophys. Res. Commun. 457, 627-634. doi: 10.1016/j.bbrc.2015.01.038

Zhao, Z., Liu, H., Wang, C., and Xu, J. R. (2013). Comparative analysis of fungal genomes reveals different plant cell wall degrading capacity in fungi. $B M C$ Genomics 14:274. doi: 10.1186/1471-2164-14-274

Zhou, Y., Liu, Y., Wang, S., Shi, C., Zhang, R., Rao, J., et al. (2017). Molecular cloning and characterization of galactinol synthases in Camellia sinensis with different responses to biotic and abiotic stressors. J. Agric. Food Chem. 65, 2751-2759. doi: 10.1021/acs.jafc.7b00377

Zhu, L. L., Zhao, X. Q., Jiang, C., You, Y., Chen, X. P., Jiang, Y. Y., et al. (2013). C-type lectin receptors Dectin-3 and Dectin-2 form a heterodimeric patternrecognition receptor for host defense against fungal infection. Immunity 39, 324-334. doi: 10.1016/j.immuni.2013.05.017

Zipfel, C. (2014). Plant pattern-recognition receptors. Trends Immunol. 35, 345-351. doi: 10.1016/j.it.2014.05.004
Zipfel, C., and Oldroyd, G. E. (2017). Plant signalling in symbiosis and immunity. Nature 543, 328-336. doi: 10.1038/nature 22009

Conflict of Interest Statement: The authors declare that the research was conducted in the absence of any commercial or financial relationships that could be construed as a potential conflict of interest.

Copyright (C) 2018 Chaliha, Rugen, Field and Kalita. This is an open-access article distributed under the terms of the Creative Commons Attribution License (CC BY). The use, distribution or reproduction in other forums is permitted, provided the original author(s) and the copyright owner(s) are credited and that the original publication in this journal is cited, in accordance with accepted academic practice. No use, distribution or reproduction is permitted which does not comply with these terms. 